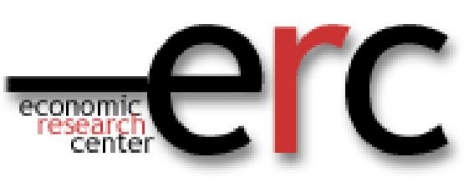

ERC Working Papers in Economics 11/05

Oct 2011

\title{
International Labor Force Participation Rates by Gender: Unit Root or Structural Breaks?
}

\author{
Zeynel Abidin Ozdemir \\ Department of Economics, Gazi University, Besevler, 06500, Ankara, TURKEY \\ e-mail: zabidin@gazi.edu.tr, Phone:+(90) 3122161115 \\ Fax: +(90) 3122132036
}

and

\section{Mehmet Balcilar}

Department of Economics, Eastern Mediterranean University, Famagusta, Turkish Republic of Northern Cyprus

e-mail: mehmet.balcilar@emu.edu.tr, Phone: +90 392630 1548×1548, Fax: +90 392365

1017

and

\section{Aysit Tansel}

Department of Economics, Middle East Technical University, 06531, Ankara, TURKEY. Institute for Study of Labor (IZA), Bonn, GERMANY

e-mail: atansel@metu.edu.tr, Phone: +(90) 31221020 57, Fax: +(90) 3122107964 


\title{
International Labor Force Participation Rates by Gender: Unit Root or Structural Breaks?
}

\author{
Zeynel Abidin Ozdemir \\ Department of Economics, Gazi University, Besevler, 06500, Ankara, TURKEY \\ e-mail: zabidin@gazi.edu.tr, Phone: +(90) 3122161115 \\ Fax: +(90) 3122132036
}

and

\section{Mehmet Balcilar}

Department of Economics, Eastern Mediterranean University, Famagusta, Turkish Republic of Northern Cyprus

e-mail: mehmet.balcilar@emu.edu.tr, Phone: +90 392630 1548×1548, Fax: +90 392365

1017

and

\section{Aysit Tansel*}

Department of Economics, Middle East Technical University, 06531, Ankara, TURKEY.

Institute for Study of Labor (IZA), Bonn, GERMANY

e-mail: atansel@metu.edu.tr, Phone: +(90) 31221020 57, Fax: +(90) 3122107964

Revised: May, 2011

JEL Codes: C22; E24; J16; J21.

Key Words: Labour Force Participation Rates; Gender; Fractional Integration, Structural Breaks.

${ }^{*}$ Corresponding author. We are grateful to the two anonymous referees and the editor Klaus G. Zauner of Bulletin of Economic Research for their useful comments. Any remaining errors are our own. 


\begin{abstract}
This paper examines the possibility of unit roots in the presence of endogenously determined multiple structural breaks in the total, female and male labour force participation rates (LFPR) for Australia, Canada and the USA. We extend the procedure of Gil-Alana (2008) for single structural break to the case of multiple structural breaks at endogenously determined dates using the principles suggested by Bai and Perron (1998). We use the Robinson (1994) LM test to determine the fractional order of integration. We find that endogenously determined structural breaks render the total, female and male LFPR series stationary or at best meanreverting.
\end{abstract}




\section{Introduction}

Recently labour economists focused on examining the time series properties of labour force participation rate (LFPR). Behind this interest lies the increasing realization that the unemployment rate may not be a good indicator of joblessness when there are variations in LFPR. LFPR may exhibit variations due to movement of individuals in and out of the labour market in response to legislative changes or business cycles. The changes in LFPR during the business cycles are referred to as "discouraged worker" and "added worker" effects observed in a number of countries. For example, during business trough, reduced employment rates reflect both the higher unemployment and the withdrawal from the labour force due to discouraged worker effect. Since unemployment rates do not take discouraged workers into account, they will not be informative about the state of the labour market. For this reason, the time series properties of the LFPR series may be more informative about the time series properties of the unemployment rates than the unemployment rate itself. The effect of the changes in unemployment rates on employment rates depends on the time series properties of the LFPR. For instance, if the LFPR series is non-stationary, that is the unemployment is characterized by hysteresis, changes in unemployment rates do not translate into changes in employment rates. This is because changes in unemployment rates will permanently shift the LFPR due to discouraged worker effect, if the LFPR series is not stationary. Therefore, increases or decreases in unemployment rates will not cause opposite changes in employment rates. Conversely, if the LFPR is stationary or mean reverting, changes in LFPR will not affect the unemployment rate since natural rate of unemployment will prevail with wage rate adjustment. The link between the informational value of the unemployment rates and the LFPR has been recently noticed by authors such as Gustavsson and Österholm (2006; 2007) and Madsen et al. (2008). Therefore, the purpose of this paper is to examine the time series properties of LFPR so as to draw inferences about informational value of unemployment. We perform this analysis for total, female, and male LFPR separately in three main OECD countries, namely Australia, Canada, and the USA. We have selected these countries to study since the time series properties of the LFPRs of these three countries are studied previously with contradictory results.

Gustavsson and Österholm (2006) use monthly data over the period 1951-2004 for Australia, Canada and the USA to examine the time series properties of total LFPR with 
univariate and panel data unit root tests but do not consider the possibility of structural breaks. They initially use a series of univariate unit root tests: the Augmented DickeyFuller (ADF) test of Said and Dickey (1984), the Augmented Dickey-Fuller test with GLS detrending of Elliott et al. (1996), the KSS test of Kapetanios et al. (2003) and the KPSS test of Kwiatkowski et al. (1992). They also test whether participation rates are stationary using two panel unit root tests: one is due to Im et al. (2003) which is based on pooled univariate ADF tests and the other is Johansen (1988) likelihood ratio tests. They find that the LFPR series of these countries are non-stationary. Madsen et al. (2008), on the other hand, use annual LFPR series for G-7 countries over the period 1870-2004. They relied on two tests: one is the unit root test in the presence of a non-linear threshold proposed by Caner and Hansen (2001) to test for mean reversion finding more mean reversion in the LFPR series than Gustavsson and Österholm (2006). The second test they use is the LM unit root test with one and two breaks in the intercept developed by Lee and Strazicich (2003; 2004) with the finding that the most of the LFPR series are trend reverting. They conclude that "there is at best mixed support that unemployment rates are informative" (Madsen et al. 2008, p.187) maintaining the conclusion of Gustavsson and Österholm (2006). Gustavsson and Österholm (2010) investigate the disaggregated LFPR series by gender, age and race for the USA. They maintain their previous finding of non-stationarity for the aggregate participation rate for all of the sub-populations they investigate using the ADF test (Said and Dickey, 1984), the ADF test with GLS detrending (Elliot et al., 1996) and the KPSS test (Kwiatkowski et al., 1992).

In recent years, researchers are increasingly using long-memory processes, such as the autoregressive fractionally integrated moving average (ARFIMA), in modelling macroeconomic time series. Such models which imply hyperbolic rate of decay better describe the dependence between increasingly distant observations in time than the stationary autoregressive and moving average (ARMA) models which imply exponential rate of decay. The implied slow decay of shocks and the very slow but eventual adjustment to equilibrium prove fractionally integrated models attractive in modelling long-memory time series. Modelling persistence of macroeconomic time series has been one of the major research areas in the last three decades. There is a growing interest in long-memory models as these models offer a viable alterative to explain the strong persistence in most economic time series. Unit root models can be seen as a specific form of long-memory. The growing interest in long-memory models has been partly due to low power of unit root and 
cointegration tests in the presence of long-memory. Strong persistence can be modelled using the long-memory models without abandoning the mean reversion and equilibrium properties of most economic models. Furthermore, fractionally integrated models may be able to describe the nonstationary series better than the usually employed differencing procedure. There are several explanations of the findings of long-memory in macroeconomic time series. Robinson (1978) and Granger (1980) show that aggregation of heterogeneous autoregressive processes results in long-memory in the aggregate series. Parke (1999) presents an error duration model that leads to a long-memory process. Diebold and Inoue (2001) develop regime-switching and structural break models that produce long-memory, which is of particular interest in this study. Engle and Smith (1999) examine the relationship between long-memory and structural breaks. Lobato and Savin (1998) present evidence that structural breaks are responsible for long-memory in return volatility. A more recent paper dealing with fractional integration and structural breaks is Granger and Hyung (2004).

In this paper we examine the time series properties of LFPR in order to asses the informational value of unemployment for Australia, Canada, and the USA. We extend the monthly data of Gustavsson and Österholm (2006) to July 2008 and consider the LFPR by gender. Our contributions include the following. First, we examine the female and male LFPR series as well as the total LFPR series. Although the issue of stationarity of LFPR is studied earlier, there are no studies that explore the time series properties of LFPR by gender except the recent study by Gustavsson and Österholm (2010) for the USA. Since the gender is an important source of worker heterogeneity in the LFPR series, there may be differences in the time series properties of the LFPR series between females and males. For instance, in the countries we are examining there was unprecedented entry of woman into the labour force in the 1970s. Further, female and male participation dynamics may differ and more importantly the degree of integration of female and male LFPR series may differ. For this reason an investigation of the time series properties of the LFPR series differentiated by gender is warranted. Our second contribution is methodological in essence. We extend previous studies of determining the order of integration in fractionally integrated models while allowing endogenously determined multiple structural breaks. GilAlana (2003) assumes the structural break dates are known and uses dummy variable to incorporate the breaks. Gil-Alana (2008) employs a procedure based on minimizing the residuals sum squared where a single structural break is allowed at an unknown date. We 
extend this procedure to the case of multiple structural breaks at unknown dates. For this, we use the procedure of Gil-Alana (2008) and the principles suggested in Bai and Perron (1998). Our procedure allows multiple structural breaks in the form of level and trend shifts at endogenously determined dates and uses the Robinson (1994) LM test to determine the fractional order of integration. Since we use a grid of finite fractional integration orders as suggested in Robinson (1994), this may lead to inconsistent estimates of break dates and fractional integration if the true fractional order is not in the finite set. Nevertheless, all previous studies using this approach face the same limitation.

The main findings of this paper are as follows. The total, female and male participation rates in Australia are stationary. The total and female participation rates for Canada and male participation rate for the USA are also stationary. The male participation rate for Canada and total and female participation rates for the USA are non-stationary but meanreverting under the preferred assumption of white noise (WN) disturbances. We find that structural breaks substantially affect the degree of integration of the total, female and male participation rates series rendering them stationary or at best mean-reverting. Thus, our results imply that unemployment rates are informative about joblessness in the labour markets of Australia, Canada and the USA. These results are contrary to the findings of Gustavsson and Österholm $(2006 ; 2010)$ and Madsen et al. (2008). Gustavsson and Österholm report that total participation rates are generated by unit root processes indicating that total participation rates are non-stationary $\mathrm{I}(1)$ for the same countries. Madsen et al. report that the evidence is at best mixed except for the total participation rate for the USA which is mean-reverting.

The rest of this paper is organized as follows. Next section provides a discussion of the methodology used in evaluating the order of integration of the LFPR series. The main properties of the LFPRs in Australia, Canada and the USA are given in Section 3. Section 4 presents the empirical results. Last section provides the concluding remarks.

\section{Methodology}

\subsection{Testing for fractional integration with structural breaks}


Robinson (1994) developed a very general procedure for testing unit roots as well as other nonstationary alternatives. Unlike the other unit root tests (Dickey and Fuller, 1979; Phillips and Perron, 1998; and many others), which test for autoregressive (AR) unit roots, Robinson's procedure allows testing for fractional order of integration in addition to other appealing hypothesis. Klemes (1974), Künsch (1986), Hidalgo and Robinson (1996), Lobato and Savin (1998), Teverovsky and Taqqu (1997) and Diebold and Inoue (2001) draw our attention to the possibility of overstating the order of fractional integration when presence of structural breaks are not taken into account. Bhattacharya et al. (1983), Teverovsky and Taqqu (1997), Granger and Hyung (2004) and Ohanissian et al. (2008) show that fractional integration may be a spurious phenomenon caused by the existence of breaks in short-memory I(0) contexts. In line with this, other authors such as Kuan and Hsu (1998), Wright (1998) and Krämer and Sibbertsen (2002) show that evidence of structural change might be spurious since most commonly employed tests for breaks are biased towards an over-rejection of the null of no change when the process exhibits long memory. This section provides a brief account of testing for fractional integration in the presence of structural breaks at unknown dates due to Robinson.

Consider the multiple regression of the form

$$
y_{t}=\beta^{\prime} z_{t}+x_{t}, \quad t=1,2, \ldots, T
$$

where $y_{t}$ is the time series we observe, $\beta$ is a $k \times 1$ vector of unknown parameters and $z_{t}$ is a $k \times 1$ vector of observable variables which could include a constant, polynomials in time trend $(t)$ and structural break dummies as we would assume in the application section of this paper. More generally, it may be a $(k x 1)$ vector of deterministic terms or even weakly exogenous variables. The presence of such deterministic regressors does not affect the limiting null and local distributions of the Robinson test statistic, which is an advantage over other unit root tests. $T$ is the sample size.

We consider a general case where $z_{t}$ includes $n_{1}$ level shift dummies $D L_{t, i}^{\ell}$ at dates $i=T_{b, 1}^{\ell}, T_{b, 2}^{\ell}, \ldots, T_{b, n_{1}}^{\ell}, \quad n_{2}$ trend shift dummies $D T_{t, i}^{\tau}$ at dates $i=T_{b, 1}^{\tau}, T_{b, 2}^{\tau}, \ldots, T_{b, n_{2}}^{\tau}$, and $2 n_{3}$ level and trend shift dummies $D L T_{t, i}^{\tau l^{\prime}}=\left(D L_{t, i}^{\tau l}, D T_{t, i}^{\tau l}\right)^{\prime}$ at the same dates $i=T_{b, 1}^{\ell \tau}, T_{b, 2}^{\ell \tau}, \ldots, T_{b, n_{3}}^{\ell \tau}$. Here $D L_{t, i}^{\ell}=1$ if $t>T_{b, i}^{\ell}$ and zero otherwise, $D T_{t, i}^{\tau}=t-T_{b, i}^{\tau}$ if $t>T_{b, i}^{\tau}$ and zero otherwise. $D L_{t, i}^{\tau l}$ and $D T_{t, i}^{\tau l}$ are defined analogously as level and trend shift 
dummies at the same date $i=T_{b, i}^{\ell \tau}$. In order to avoid duplicates we require $T_{b, i}^{\ell} \neq T_{b, i}^{\tau} \neq T_{b, i}^{\ell \tau}$ for all possible values of $i$. For brevity we define $T_{b}$ as the set of disjoint break dates $T_{b}=\left\{T_{b, 1}^{\ell}, \ldots, T_{b, n_{1}}^{\ell}, T_{b, 1}^{\tau}, \ldots, T_{b, n_{2}}^{\tau}, T_{b, 1}^{\ell \tau}, \ldots, T_{b, n_{3}}^{\ell \tau}\right\}$. Now we can define $\beta^{\prime} z_{t}$ as follows:

$$
\beta^{\prime} z_{t}=\sum_{i=1}^{n_{1}} \alpha_{i} D L_{t, i}^{\ell}+\sum_{j=1}^{n_{2}} \gamma_{j} D T_{t, j}^{\tau}+\sum_{l=1}^{n_{3}}\left(\phi_{l} D L_{t, l}^{\ell \tau}+\theta_{l} D T_{t, l}^{\ell \tau}\right)
$$

The regression errors $x_{t}$ are given by:

$$
(1-L)^{d} x_{t}=u_{t},
$$

where $L$ is the lag operator, $u_{t}$ is an integrated of order zero, $\mathrm{I}(0)$, covariance stationary process with spectral density function which is positive and finite at zero frequency. The order of integration $d$ is not restricted to integer values and can take any value on the real line. Indeed, our specification covers any stationary autocorrelated process not only AR(1). Broader processes are also possible in implementing the test. "I $(0)$, covariance stationary process" includes $\operatorname{AR}(1)$ as well as any stationary $\operatorname{ARMA}(p, q)$ process. We define the $(1-L)^{d}$ by means of the binomial expansion. The value of $d$ is the major interest in our case. For $0<d<0.5, y_{t}$ is covariance stationary and invertible, but it has long memory since its covariance function displays a hyperbolic decay-slower decay than exponential decay form of a weakly stationary time series - and not absolutely summable. The unit root case is obtained with $d=1$. If $d=0$, the process is short memory, and if $d<0, y_{t}$ is antipersistent. When $d \leq-0.5, y_{t}$ is covariance stationary but not invertible. For $d \geq 0.5, y_{t}$ is nonstationary and has infinite variance. For macroeconomic applications a particularly interesting interval for $d$ is $0.5<d<1$, where $y_{t}$ displays strong persistence, but mean reverts in the sense that the impulse response function is decaying. When $y_{t}$ is mean reverting, it will eventually return to its mean in the face of a shock, although this may take a long time due to the presence of long-memory (Granger and Joyeux, 1980; Hosking, 1981).

The idea behind this model with structural breaks is based on the least square principle proposed by Bai and Perron (1998). First, a grid of values $d_{0}=0,0.05, \ldots, 1$ is chosen for $d$. Then, the parameter $n=n_{1}+n_{2}+n_{3}$ is the number of structural breaks. The break dates $T_{b}$ are explicitly treated as unknown for $i=1,2, \ldots, n_{1}, j=1,2, \ldots, n_{2}$, and 
$l=1,2, \ldots, n_{3}$. Following the procedure as in Bai and Perron (1998) for each $k$-partition, $\left\{T_{1}, \ldots, T_{k}\right\}, k=1,2, \ldots, n+1$, denoted $\left\{T_{k}\right\}$, the least squares estimates of $\alpha_{i}, \gamma_{j}, \phi_{l}$ and $\theta_{l}$ are obtained by minimizing the sum of squared residuals in the $d_{0}$-differenced models, that is the residuals sum of squares (RSS)

$$
\sum_{t=1}^{T}(1-L)^{d_{0}}\left(y_{t}-\sum_{i=1}^{n_{1}} \alpha_{i} D L_{t, i}^{\ell}-\sum_{j=1}^{n_{2}} \gamma_{j} D T_{t, j}^{\tau}-\sum_{l=1}^{n_{3}}\left(\phi_{l} D L_{t, l}^{\ell \tau}+\theta_{l} D T_{t, l}^{\ell \tau}\right)\right)^{2}
$$

is minimized over all values of $\left\{T_{1}, \ldots, T_{k}\right\}$ yielding estimates $\hat{\alpha}_{i}, \hat{\gamma}_{j}, \hat{\phi}_{l}, \hat{\theta}_{l}$ and break dates $\left\{\hat{T}_{k}\right\}$. The above procedure requires a prior determination of the number of breaks $n$. We use Schwarz's (1978) Bayesian information criterion (BIC) to select the number of breaks. Accordingly number of breaks $n$ is chosen to minimize the criterion $\operatorname{BIC}(n)=\ln \left[\operatorname{RSS}\left(\hat{T}_{k}\right) /(T-n)\right]+2 n \ln (T) / T$. The fractional order of differencing $d$ is determined by calculating the test statistics of Robinson (1994) for each value of $d_{0}$ in the grid. This procedure is outlined below.

In order to test the null hypothesis:

$$
H_{0}: d=d_{0},
$$

Robinson (1994) developed the following score test statistic:

$$
\hat{r}=\left(\frac{T^{1 / 2}}{\hat{\sigma}^{2}}\right) \hat{A}^{-1 / 2} \hat{a}
$$

where

$$
\begin{gathered}
\hat{a}=-\frac{2 \pi}{T} \sum_{j=1}^{T-1} \psi\left(\lambda_{j}\right) g\left(\lambda_{j} ; \eta\right) I\left(\lambda_{j}\right), \quad I\left(\lambda_{j}\right)=\frac{1}{2 \pi T}\left|\sum_{t=1}^{T} \hat{u}_{t} e^{i \lambda_{j} t}\right|^{2}, \quad \lambda_{j}=\frac{2 \pi j}{T} \\
\hat{\sigma}^{2}=(2 \pi / T) \sum_{j=1}^{T-1} g\left(\lambda_{j} ; \hat{\eta}\right) I\left(\lambda_{j}\right) . \\
\hat{A}=\frac{2}{T}\left(\sum_{j=1}^{T-1} \psi\left(\lambda_{j}\right) \psi\left(\lambda_{j}\right)^{\prime}-\sum_{j=1}^{T-1} \psi\left(\lambda_{j}\right) \hat{\xi}\left(\lambda_{j}\right)^{\prime} \times\left(\sum_{j=1}^{T-1} \hat{\xi}\left(\lambda_{j}\right) \hat{\xi}\left(\lambda_{j}\right)^{\prime}\right)^{-1} \times \sum_{j=1}^{T-1} \hat{\xi}\left(\lambda_{j}\right) \psi\left(\lambda_{j}\right)^{\prime}\right) \\
\hat{\xi}\left(\lambda_{j}\right)=\frac{\partial}{\partial \eta} \log g\left(\lambda_{j} ; \hat{\eta}\right), \quad \psi\left(\lambda_{j}\right)=\operatorname{Re}\left\{\frac{\partial}{\partial \delta} \log \varphi\left(e^{-i \lambda_{j}} ; \delta_{0}\right)\right\}
\end{gathered}
$$

and $I\left(\lambda_{j}\right)$ is the periodogram of $\hat{u}_{t} \cdot g\left(\lambda_{j} ; \eta\right)$ is a known function of the parametric spectral density of $u_{t}$. For fractional alternatives we have 
$\varphi(z ; \delta)=(1-z)^{v_{1}+\delta_{i_{1}}}(1-z)^{v_{1}+\delta_{i_{2}}} \times \prod_{j=3}^{h}\left(1-2 \cos \lambda_{j} z+z^{2}\right)^{v_{j}+\delta_{i_{j}}}$

for given $h$; for given real distinct numbers $v_{1}, v_{2}, \ldots, v_{h}$, where for each $j \delta_{i j}=\delta_{l}$ for some $l$, and for each $l$ there is at least one $j$ such that $\delta_{i j}=\delta_{l}$. When $x_{\mathrm{t}}$ is fractionally integrated, i.e., $(1-L)^{d} x_{t}=u_{t}$, the expression for $\psi\left(\lambda_{j}\right)$ reduces to $\psi\left(\lambda_{j}\right)=\log \left|2 \sin \left(\lambda_{j} / 2\right)\right|$. The parameter estimates $\hat{\eta}$ are obtained with the Whittle Maximum Likelihood (WML) method, which is obtained by

$$
\hat{\eta}=\arg \min _{\eta \in \Lambda} \frac{2 \pi}{T} \sum_{j=1}^{T-1} g\left(\lambda_{j} ; \eta\right) I\left(\lambda_{j}\right) .
$$

In this paper, the model for $u_{t}$ is restricted to the cases nested within an autoregressive moving average (ARMA) model with $g\left(\lambda_{j}, \eta\right)=2 \pi f\left(\lambda ; \sigma^{2}, \eta\right) / \sigma^{2}$ where $f\left(\lambda ; \sigma^{2}, \eta\right)$ is its spectral density. First, the residuals $\hat{u}_{t}=(1-L)^{d_{0}} \hat{x}_{t}=(1-L)^{d_{0}} y_{t}-\hat{\beta}^{\prime}\left[(1-L)^{d_{0}} z_{t}\right]$ are estimated using the endogenously determined structural break dates as outlined above. Then, at each step of minimization of $\operatorname{RSS}\left(\hat{T}_{k}\right)$ for given $d_{0}$ the nuisance parameters $\hat{\eta}$ is estimated from (6).

Under certain regularity conditions and the null hypothesis given above, Robinson (1994) showed that $\hat{r}$ approaches normal distribution with zero mean and variance one as $T$ approaches infinity. Note that this limiting distribution holds independently of the regressors included in $z_{t}$ and the various types of $\mathrm{I}(0)$ disturbances assumed for $u_{t}$, which includes the general weakly stationary ARMA models. Robinson shows that the test statistic $\hat{r}$ is efficient in the Pitman sense. An approximate one-sided test of $H_{0}: d=d_{0}$ is rejected in favor of $H_{1}: d>d_{0}\left(d<d_{0}\right)$ at the $\alpha$ level of significance, when $\hat{r}>z_{\alpha}$, $\left(\hat{r}<-z_{\alpha}\right)$, where $\alpha$ is the probability that a standard normal variate exceeds $z_{\alpha}$. This and other versions of the Robinson (1994) test are used in empirical applications recently by Gil-Alana and Robinson (1997, 2001) and Gil-Alana (1999, 2001a, 2001b, 2002).

\subsection{Measuring persistence in long-memory models}

Although the presence of statistically significant $d$ is commonly interpreted to mean that $y_{t}$ is a persistent time series (see for instance Baum, Barkoulas, Caglayan (1999)), $d$ alone is not an informative criterion about the persistence of the shocks. In order to 
measure the strength of the persistence we also employ the impulse response function of an ARFIMA model to measure persistence. An impulse response function $c_{k}$ measures the effect of a unit shock at time $t$ on $y_{t+k}$. Impulse responses of a stationary process are the coefficients of its infinite order moving average representation. For a stationary ARFIMA model the impulse responses are given by the coefficients $c_{k}$ of

$$
C(L)=(1-L)^{-d} \phi(L)^{-1} \theta(L)=1+c_{1} L+c_{2} L^{2}+\cdots
$$

where $\phi(L)=1-\sum_{i=1}^{p} \phi_{i} L^{i}$ and $\theta(L)=1+\sum_{i=1}^{q} \theta_{i} L^{i}$ are autoregressive and moving average polynomials in the lag operator $L$, respectively. In this representation, the value taken by $c_{k}=\partial y_{t+k} / \partial \varepsilon_{t}$ measures the effect of a unit shock at time $t$ on $y_{t+k}$. Another useful measure of persistence may be based on how fast the effects of shocks to $y_{t}$ dissipate. Therefore, in addition to $c_{k}$ we use

$$
\tau_{\alpha}=\sup _{k}\left|\partial y_{t+k} / \partial \varepsilon_{t}\right| \leq 1-\alpha, \quad 0<\alpha<1
$$

as a measure of persistence. $\tau_{\alpha}$ aims to show the time required for a fraction $\alpha$ of the full effect of a unit shock to disappear. For $\alpha=0.5, \tau_{\alpha}$ is the period beyond which $\left|\partial y_{t+k} / \partial \varepsilon_{t}\right|$ no longer exceed 0.5 , which is the half life of a shock. The measure $\tau_{\alpha}$ is independent of prior choice of $k$. $k$ will be automatically determined once we decide on the value of $\alpha$. Therefore, both $c_{k}$ and $\tau_{\alpha}$ are appropriate for ARFIMA models as a measure of persistence.

\section{Data Properties and Description}

Seasonally adjusted monthly data on the total, female and male LFPR for Australia, Canada and the USA are obtained from web site of official statistical institute of each country. LFPR is defined as the proportion of the population that is in the labour force which comprises all persons classified as employed or unemployed - but actively looking for a job - in accordance with certain criteria. There are minor differences in these criteria among the three countries. These monthly data start in February 1978, January 1976 and January 1951 respectively for Australia, Canada and the USA and end in July 2008. Thus, there are 366, 391, and 691 monthly observations on the total, female and male LFPR, 
respectively for Australia, Canada and the USA. Figures 1, 2 and 3 present the time series plots of the total, female and male LFPR of Australia, Canada and the USA, respectively.

Ozdemir et al. (2010) discuss in detail some of the factors that might be at work in generating apparent or real breaks in these data. These factors may include methodological changes, legislative changes, compositional changes and cyclical and secular factors. For the methodological changes mostly the series were revised back in all three countries. Two very important compositional changes were the unprecedented increase in the female labour force participation and some declines in the male labour force participation, so that in all three countries we consider labour force has become more "feminized". In all three countries we observe a general declining trend in the male LFPR, increasing trend in female LFPR and the trend in total FLPR is dominated by the female LFPR, and therefore decreasing because of the increase in participation among women in all three countries. Further, the movement of the baby-boom generation (those born between 1946 and 1964 with the peak birth year 1957) into high-participation-rate ages contributed to the rising trend in the USA. In Australia the "equal pay for work of equal value" adopted in 1969 with major amendments to it in 1972 may have affected employment opportunities for women, and, thus, their labour force participation rate. Similarly, over the years the USA has expanded disability programs, which has resulted in a decline in male participation. The USA has also changed both the benefit levels and the eligibility requirements for Social Security payments, which resulted in a decline in participation rates in older age groups. Most of the decline in the participation of older Americans is attributed to rising social security wealth. Anderson et al. (1997) found that about a quarter of the reduction in men's full-time employment during the 1969-1989 period was due to employer pension plans and social security together. Increases in the gross replacement ratio substantially in all three countries over the 1961-1995 period contributed to the decline in participation rates of the older ages. In Canada from 2003 onwards a relatively slower growth in the LFPR has been attributed to several reasons such as the shortage of workers and an aging labour force. For the USA after 2001 the overall participation rate entered a declining phase due to three factors. First, the first baby boomers entered age 55 in 2001, which is the beginning age of traditionally lower participation rates. Second, the dramatic increase in the female LFPR of the previous periods has also flattened out in recent years. Finally, the economic crises which began in March, 2001 caused a decline in LFPR. 
Figure 1: Time Series Plot of LFPR for Australia

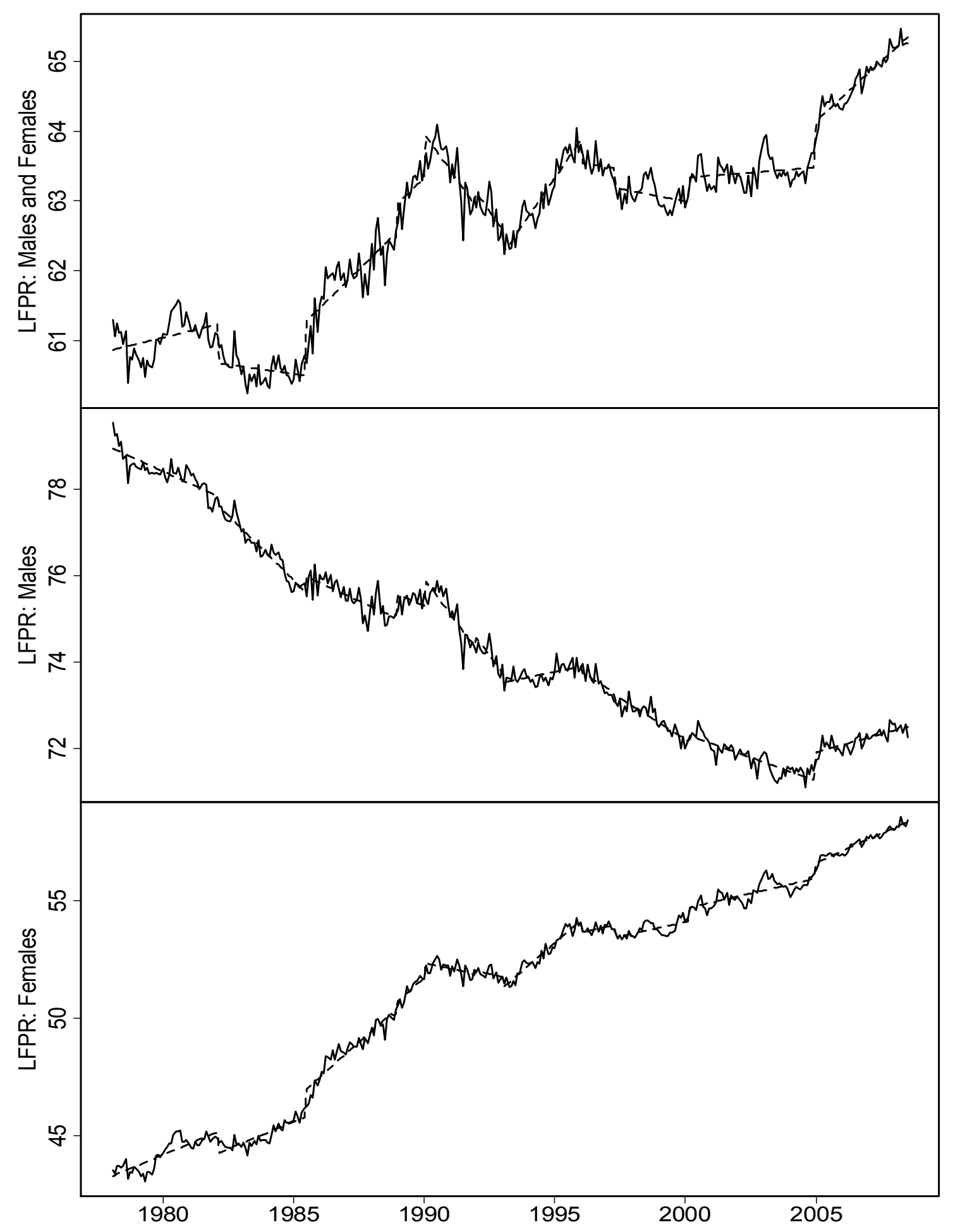


Figure 2: Time Series Plot of LFPR for Canada

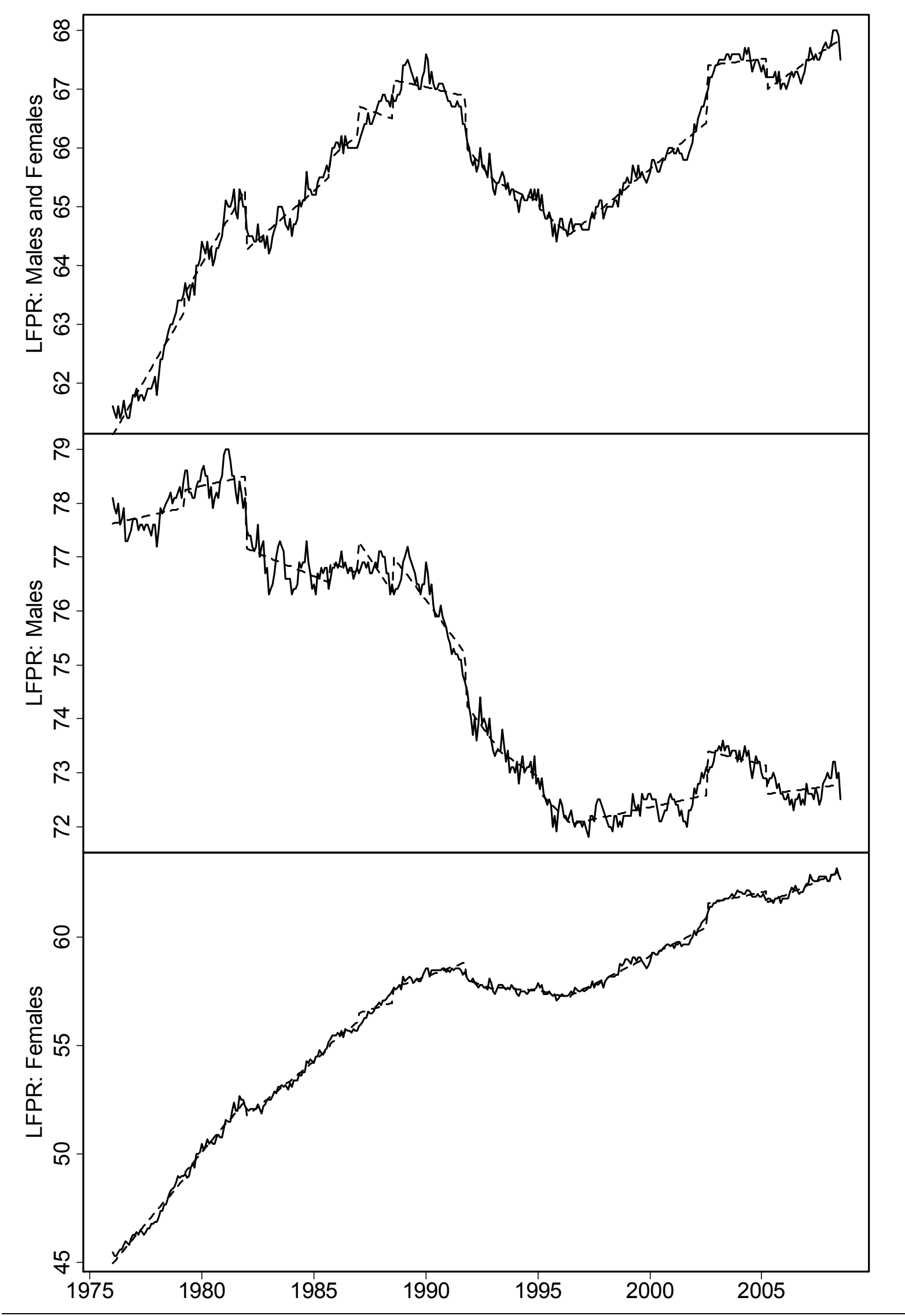


Figure 3: Time Series Plot of LFPR for the USA

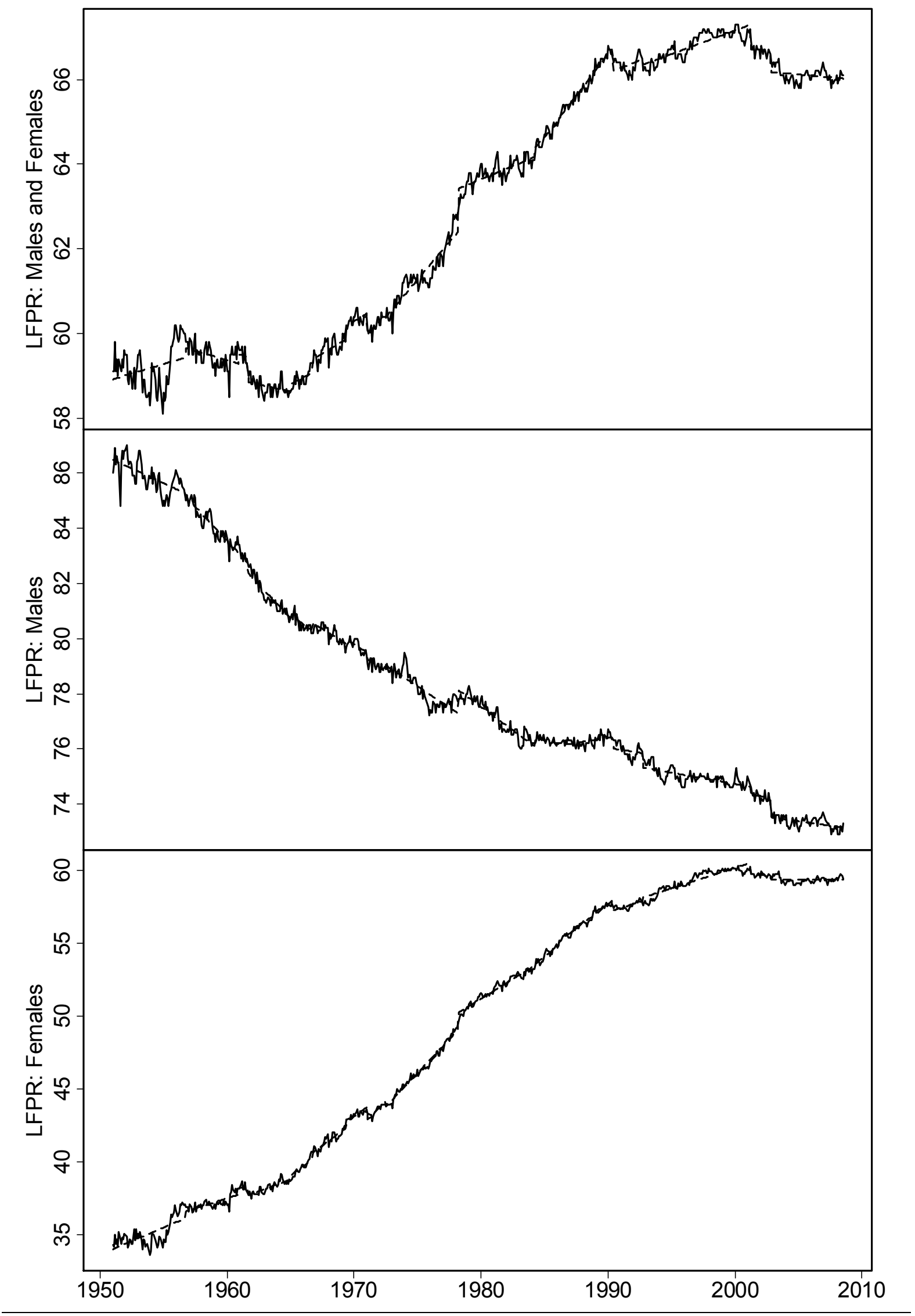


Most of the breaks that we endogenously indentified are the consequences of the business cycle factors. Our computations indicate that the break point dates that are endogenously identified for the total LFPR are exactly the same as the endogenously identified break point dates in the female and male LFPRs. This indicates robustness of our computations. These endogenously determined structural change dates are given in Table 1 for the three countries.

\section{Empirical Results}

A number of researches showed that apparent non-stationarity may be caused by neglected structural changes. These include Perron (1989, 1997), Zivot and Andrews (1992), Banerjee et al. (1992), Christiano (1992), Perron and Vogelsang (1992), Balcilar (1996), Lumsdaine and Papell (1997), Clemente et al. (1998), Ohara (1999) and Kapetanios (2005). The stochastic permanent shifts mimic the effect of a persistent shock. Therefore, the long-memory models with occasional shifts may incorrectly find evidence of long-memory. In contrast, the STOPBREAK model of Engle and Smith (1999) is more flexible and models the level shifts as a component with stochastic permanent shifts. Bos et al. (1999) attempt to capture the effect of level shifts by inclusion of dummy variables. In this paper, we allow endogenously determined multiple structural breaks in a fractionally integrated process to examine the series of total, female and male LFPR in Australia, Canada and the USA.

Figures 1, 2 and 3 show the time series plot of total, female and male LFPR series of Australia, Canada and the USA, which suggest that the LFPR series have undergone several structural changes over the period of examination. The dashed lines indicate the level and trend shifts identified by our procedure. As discussed in section 3, the possible causes of the structural changes are mostly cyclical factors in the economy. For the total, female and male LFPR series, we will be testing the null hypothesis $H_{0}: d=d_{0}$ in equations (1) and (2) with $d_{0}=\{0.00,0.05, \ldots, 0.95,1.00\}$. The dummy variables describing these structural break points are defined in Section 2.1. Accordingly, $z_{1 t}=\left(1, t, D L_{t, 1}^{\tau l}, \ldots, D L_{t, n_{3}}^{\tau l}, D T_{t, i}^{\tau l}, \ldots, D T_{t, n_{3}}^{\tau l}\right)^{\prime}$ is defined as the regressors in equation (1) with constant, time trend, trend and level shift dummy variables $D L_{t, i}^{\tau l}$ and $D T_{t, i}^{\tau l}$ for each structural break point $i=1, \ldots, n_{3}$, where $n_{3}$ is the endogenously determined number of 
simultaneous level and trend breaks. Similarly, $z_{2 t}=\left(z_{1 t}, D T_{t, 1}^{\tau}, \ldots, D T_{t, n_{2}}^{\tau}\right)^{\prime}$ defines the same with $z_{1 t}$ and trend shift dummy variable $D T_{t, i}^{\tau}$ for each structural break point $i=1, \ldots, n_{2}$ where $n_{2}$ is the endogenously determined number of trend shifts. Finally, $z_{3 t}=\left(z_{2 t}, D L_{t, 1}^{\ell}, \ldots, D L_{t, n_{1}}^{\ell}\right)^{\prime}$ defines the same with $z_{2 t}$ and level shift dummy variable $D L_{t, i}^{\ell}$ for each structural break point $i=1, \ldots, n_{1}$ where $n_{1}$ is the endogenously determined number of level shifts. Regression estimates of the parameters $\alpha_{i}, \gamma_{j}, \phi_{l}$ and $\theta_{l}$ corresponding to the structural break dummies are prohibitively large for reporting. The total number of regression estimates for tests reported in Table 2 is $2,268(6 \times 18 \times 21=2,268$, where 21 is the number of $d_{0}$ considered under the null). Incidentally in the context of the deterministic dummies for the breaks, the coefficients of these dummies are all statistically significant at five percent level or better. These results are available from the authors upon request.

Table 1: Endogenously determined Structural Change Dates

\begin{tabular}{|c|c|c|c|}
\hline Australia & Level Shift Date & Trend Shift Date & Trend and Level Shift Date \\
\hline Total & $\begin{array}{c}\text { December } 1988 \\
\text { December } 1991 \\
\text { May } 1997\end{array}$ & $\begin{array}{c}\text { October } 1988 \\
\text { October } 1991 \\
\text { April } 1997\end{array}$ & $\begin{array}{c}\text { February } 1982 \\
\text { July } 1985 \\
\text { January } 1990 \\
\text { January } 1993 \\
\text { January } 1996 \\
\text { February 2000 } \\
\text { December 2004 }\end{array}$ \\
\hline Female & Same as above & Same as above & Same as above \\
\hline Male & Same as above & Same as above & Same as above \\
\hline Canada & & & \\
\hline Total & $\begin{array}{c}\text { March } 1979 \\
\text { September } 1985 \\
\text { October } 1991 \\
\text { January } 1995 \\
\text { March } 2005\end{array}$ & $\begin{array}{c}\text { July } 1988 \\
\text { October } 1991 \\
\text { January } 1995 \\
\text { March } 2005\end{array}$ & $\begin{array}{c}\text { December } 1981 \\
\text { December } 1986 \\
\text { March } 1993 \\
\text { July } 1996 \\
\text { June } 2002\end{array}$ \\
\hline Female & Same as above & Same as above & Same as above \\
\hline Male & Same as above & Same as above & Same as above \\
\hline \multicolumn{4}{|l|}{$U S A$} \\
\hline Total & $\begin{array}{l}\text { August } 1961 \\
\text { May } 1969 \\
\text { February } 1986 \\
\text { October } 2002\end{array}$ & $\begin{array}{c}\text { December } 1960 \\
\text { September } 1966 \\
\text { June } 1972 \\
\text { February } 1986 \\
\text { September } 1992 \\
\text { May } 2002\end{array}$ & $\begin{array}{c}\text { September } 1956 \\
\text { January } 1965 \\
\text { January } 1971 \\
\text { March } 1978 \\
\text { March } 1984 \\
\text { May } 1990 \\
\text { March 2001 }\end{array}$ \\
\hline Female & Same as above & Same as above & Same as above \\
\hline Male & Same as above & Same as above & Same as above \\
\hline
\end{tabular}


Table 2 gives the values of the one-sided test statistic $\hat{r}$ defined in equation (4) for total, female and male LFPR of Australia, Canada and the USA in the parenthesises. The associated $d_{0}$ values are reported before the parenthesises. In order to save space only those vales of $\hat{r}$ and the associated $d_{0}$ for which the null hypothesis $H_{0}: d=d_{0}$ are not rejected are reported. In these tables Panel (a) assumes that $u_{t}$, the disturbances in equation (2), are a white noise process while Panel (b) assumes that they are first order autoregressive, $\mathrm{AR}(1)$, process. One should anticipate a monotonic decrease in the value of the $\hat{r}$ statistic with increasing $d$ values. The columns for $z_{t}=0$ and $z_{t}=1$ are the cases of no deterministic term and only a constant term, respectively. $z_{t}=(1, t)^{\prime}$ is the case of a constant and a linear time trend term. $z_{1 t}, z_{2 t}$ and $z_{3 t}$ are the cases described in the previous paragraph.

Table 2, Panel (a) gives the case for total LFPR for Australia. The null hypothesis of $d$ $=0$ is rejected at 5\% significance level in favour of a positive $d$ for all cases of $z_{t}$ considered. However, $d=0.95$ and $d=1$ are not rejected for $z_{t}=0$. When we include a constant term $\left(z_{t}=1\right)$, the values of $d$ that are not rejected are reduced to 0.80 and 0.85 . Consideration of a constant and a linear time trend $\left(z_{t}=(1, t)^{\prime}\right)$, further reduces the values of $d$ under the null hypothesis that are not rejected. Further consideration of cases $z_{1 t}, z_{2 t}$ and $z_{3 t}$, where endogenously determined structural breaks are taken into account by including level and trend shift dummies or both, indicate further reductions in the values of $d$ under which the null hypothesis are not rejected. The last column of Panel (a) indicates a value of 0.30 for $d$ that is not rejected. Similar considerations of Panel (b) lead to a value of 0.35 for $d$ that is not rejected. These results suggest that the LFPR series for Australia is a stationary series with long-memory. 
Table 2: Testing for Fractional Integration for total, female and male LFPR for Australia, Canada and the USA

\begin{tabular}{|c|c|c|c|c|c|c|}
\hline & $z_{t}=0$ & $z_{t}=1$ & $z_{t}=(1, t)^{\prime}$ & $z_{t}=z_{1 t}$ & $z_{t}=z_{2 t}$ & $z_{t}=z_{3 t}$ \\
\hline \multicolumn{7}{|c|}{ Panel (a): Disturbances in equation (2) are assumed to be white noise } \\
\hline \multicolumn{7}{|c|}{ Australia } \\
\hline Total & $0.95^{\mathrm{a}}(1.00) \ldots 1.00^{\mathrm{b}}(-0.33)$ & $0.80^{\mathrm{a}}(0.48) \ldots 0.85^{\mathrm{b}}(-1.27)$ & $0.70^{\mathrm{a}}(1.46) \ldots 0.75^{\mathrm{b}}(-0.39)$ & $0.35^{\mathrm{a}}(1.11) \ldots 0.50^{\mathrm{b}}(-1.59)$ & $0.30^{\mathrm{a}}(1.37) \ldots 0.45^{\mathrm{b}}(-1.27)$ & $0.30^{\mathrm{a}}(0.96) \ldots 0.45^{\mathrm{b}}(-1.58)$ \\
\hline Female & $0.95^{\mathrm{a}}(1.23) \ldots 1.00^{\mathrm{b}}(-0.18)$ & $0.90^{\mathrm{a}}(1.14) \ldots 1.00^{\mathrm{b}}(-1.59)$ & $0.75^{\mathrm{a}}(1.33) \ldots 0.80^{\mathrm{b}}(-0.43)$ & $0.45^{\mathrm{a}}(0.99) \ldots 0.60^{\mathrm{b}}(-1.59)$ & $0.40^{\mathrm{a}}(1.52) \ldots 0.55^{\mathrm{b}}(-1.14)$ & $0.40^{\mathrm{a}}(1.38) \ldots 0.55^{\mathrm{b}}(-1.25)$ \\
\hline Male & $0.95^{\mathrm{a}}(0.88) \ldots 1.00^{\mathrm{b}}(-0.41)$ & $0.80^{\mathrm{a}}(0.75) \ldots 0.85^{\mathrm{b}}(-0.81)$ & $0.65^{\mathrm{a}}(1.23) \ldots 0.70^{\mathrm{b}}(-0.72)$ & $0.25^{\mathrm{a}}(1.32) \ldots 0.40^{\mathrm{b}}(-1.51)$ & $0.20^{\mathrm{a}}(1.21) \ldots 0.35^{\mathrm{b}}(-1.37)$ & $0.15^{\mathrm{a}}(1.47) \ldots 0.30^{\mathrm{b}}(-1.11)$ \\
\hline \multicolumn{7}{|l|}{ Canada } \\
\hline Total & $0.95^{\mathrm{a}}(1.00) \ldots 1.00^{\mathrm{b}}(-0.39)$ & $1.00^{\mathrm{a}, \mathrm{b}}(0.49)$ & $0.95^{\mathrm{a}}(1.15) \ldots 1.00^{\mathrm{b}}(-0.29)$ & $0.55^{\mathrm{a}}(0.84) \ldots 0.65^{\mathrm{b}}(-1.10)$ & $0.45^{\mathrm{a}}(1.63) \ldots 0.60^{\mathrm{b}}(-1.10)$ & $0.45^{\mathrm{a}}(1.05) \ldots 0.60^{\mathrm{b}}(-1.31)$ \\
\hline Female & $0.95^{\mathrm{a}}(1.16) \ldots 1.00^{\mathrm{b}}(-0.32)$ & $0.95^{\mathrm{a}}(1.58) \ldots 1.00^{\mathrm{b}}(0.24)$ & $0.95^{\mathrm{a}}(1.42) \ldots 1.00^{\mathrm{b}}(-0.03)$ & $0.50^{\mathrm{a}}(1.32) \ldots 0.60^{\mathrm{b}}(-0.90)$ & $0.45^{\mathrm{a}}(1.07) \ldots 0.55^{\mathrm{b}}(-0.94)$ & $0.40^{\mathrm{a}}(1.50) \ldots 0.55^{\mathrm{b}}(-1.26)$ \\
\hline Male & $0.95^{\mathrm{a}}(0.91) \ldots 1.00^{\mathrm{b}}(-0.43)$ & $0.85^{\mathrm{a}}(0.07) \ldots 0.90^{\mathrm{b}}(-1.48)$ & $0.85^{\mathrm{a}}(0.42) \ldots 0.90^{\mathrm{b}}(-1.07)$ & $0.55^{\mathrm{a}}(1.14) \ldots 0.70^{\mathrm{b}}(-1.35)$ & $0.50^{\mathrm{a}}(1.37) \ldots 0.65^{\mathrm{b}}(-0.99)$ & $0.50^{\mathrm{a}}(1.05) \ldots 0.65^{\mathrm{b}}(-1.12)$ \\
\hline \multicolumn{7}{|l|}{ USA } \\
\hline Total & $1.00^{\mathrm{a}, \mathrm{b}}(-0.16)$ & $0.85^{\mathrm{a}, \mathrm{b}}(-0.08)$ & $0.75^{\mathrm{a}}(1.49) \ldots 0.80^{\mathrm{b}}(-0.87)$ & $0.55^{\mathrm{a}}(1.06) \ldots 0.65^{\mathrm{b}}(-1.64)$ & $0.55^{\mathrm{a}}(0.84) \ldots 0.60^{\mathrm{b}}(-0.56)$ & $0.50^{\mathrm{a}}(1.64) \ldots 0.60^{\mathrm{b}}(-1.12)$ \\
\hline Female & $1.00^{\mathrm{a}, \mathrm{b}}(-0.24)$ & $0.95^{\mathrm{a}}(0.56) \ldots 1.00^{\mathrm{b}}(-1.13)$ & $0.80^{\mathrm{a}, \mathrm{b}}(-0.12)$ & $0.55^{\mathrm{a}}(1.48) \ldots 0.65^{\mathrm{b}}(-1.41)$ & $0.55^{\mathrm{a}}(1.12) \ldots 0.60^{\mathrm{b}}(-0.37)$ & $0.55^{\mathrm{a}}(0.70) \ldots 0.60^{\mathrm{b}}(-0.75)$ \\
\hline Male & $1.00^{\mathrm{a}, \mathrm{b}}(-0.08)$ & $0.95^{\mathrm{a}}(-0.05) \ldots 1.00^{\mathrm{b}}(-1.60)$ & $0.70^{\mathrm{a}}(1.31) \ldots 0.75^{\mathrm{b}}(-0.69)$ & $0.50^{\mathrm{a}}(0.88) \ldots 0.60^{\mathrm{b}}(-1.57)$ & $0.45^{\mathrm{a}}(1.57) \ldots 0.55^{\mathrm{b}}(-0.82)$ & $0.45^{\mathrm{a}}(0.93) \ldots 0.55^{\mathrm{b}}(-1.31)$ \\
\hline \multicolumn{7}{|c|}{ Panel (b): Disturbances in equation (2) are assumed to be an AR(1) process } \\
\hline \multicolumn{7}{|c|}{ Australia } \\
\hline Total & $\ldots>1^{\mathrm{c}}$ & $0.80^{\mathrm{a}, \mathrm{b}}(-1.43)$ & $0.70^{\mathrm{a}, \mathrm{b}}(0.80)$ & $0.40^{\mathrm{a}}(0.64) \ldots 0.45^{\mathrm{b}}(-1.54)$ & $0.35^{\mathrm{a}}(1.50) \ldots 0.40^{\mathrm{b}}(-0.61)$ & $0.35^{\mathrm{a}}(0.61) \ldots 0.40^{\mathrm{b}}(-1.45)$ \\
\hline Female & $\ldots>1^{\mathrm{c}}$ & $\ldots>1^{\mathrm{c}}$ & $0.75^{\mathrm{a}, \mathrm{b}}(1.17)$ & $0.50^{\mathrm{a}}(0.56) \ldots 0.55^{\mathrm{b}}(-1.51)$ & $0.50^{\mathrm{a}, \mathrm{b}}(-0.30)$ & $0.45^{\mathrm{a}}(1.50) \ldots 0.50^{\mathrm{b}}(-0.60)$ \\
\hline Male & $\ldots>1^{\mathrm{c}}$ & $0.80^{\mathrm{a}, \mathrm{b}}(0.66)$ & $0.65^{\mathrm{a}, \mathrm{b}}(0.02)$ & $0.30^{\mathrm{a}}(1.00) \ldots 0.35^{\mathrm{b}}(-1.29)$ & $0.25^{\mathrm{a}}(1.29) \ldots 0.30^{\mathrm{b}}(-0.80)$ & $0.25^{\mathrm{a}, \mathrm{b}}(-0.10)$ \\
\hline \multicolumn{7}{|l|}{ Canada } \\
\hline Total & $\ldots>1^{\mathrm{c}}$ & $1.00^{\mathrm{a}, \mathrm{b}}(-1.34)$ & $0.95^{\mathrm{a}, \mathrm{b}}(0.36)$ & $0.60^{\mathrm{a}, \mathrm{b}}(0.30)$ & $0.55^{\mathrm{a}}(0.46) \ldots 0.60^{\mathrm{b}}(-1.52)$ & $0.55^{\mathrm{a}, \mathrm{b}}(-0.15)$ \\
\hline Female & $\ldots>1^{\mathrm{c}}$ & $1.00^{\mathrm{a}, \mathrm{b}}(0.82)$ & $\ldots>1^{\mathrm{c}}$ & $0.55^{\mathrm{a}, \mathrm{b}}(0.62)$ & $0.50^{\mathrm{a}}(0.63) \ldots 0.55^{\mathrm{b}}(-1.63)$ & $0.50^{\mathrm{a}}(-0.20) \ldots 0.55^{\mathrm{b}}(-2.20)$ \\
\hline Male & $\ldots>1^{\mathrm{c}}$ & $0.85^{\mathrm{a}, \mathrm{b}}(-0.09)$ & $0.85^{\mathrm{a}, \mathrm{b}}(-0.71)$ & $0.60^{\mathrm{a}}(1.48) \ldots 0.65^{\mathrm{b}}(-0.53)$ & $0.60^{\mathrm{a}}(0.51) \ldots 0.65^{\mathrm{b}}(-1.28)$ & $0.60^{\mathrm{a}}(0.14) \ldots 0.65^{\mathrm{b}}(-1.55)$ \\
\hline \multicolumn{7}{|l|}{ USA } \\
\hline Total & $\ldots>1^{\mathrm{c}}$ & $0.85^{\mathrm{a}, \mathrm{b}}(-1.25)$ & $\ldots>1^{\mathrm{c}}$ & $0.60^{\mathrm{a}, \mathrm{b}}(-0.63)$ & $0.60^{\mathrm{a}, \mathrm{b}}(-1.05)$ & $0.55^{\mathrm{a}, \mathrm{b}}(0.79)$ \\
\hline Female & $\ldots>1^{\mathrm{c}}$ & $\ldots>1^{\mathrm{c}}$ & $\ldots>1^{\mathrm{c}}$ & $0.60^{\mathrm{a}, \mathrm{b}}(-0.07)$ & $0.60^{\mathrm{a}, \mathrm{b}}(-0.80)$ & $0.60^{\mathrm{a}, \mathrm{b}}(-1.58)$ \\
\hline Male & $\ldots>1^{\mathrm{c}}$ & $0.95^{\mathrm{a}, \mathrm{b}}(-1.63)$ & $\ldots>1^{\mathrm{c}}$ & $0.55^{\mathrm{a}, \mathrm{b}}(-0.10)$ & $0.55^{\mathrm{a}, \mathrm{b}}(-0.88)$ & $0.50^{\mathrm{a}, \mathrm{b}}(0.54)$ \\
\hline
\end{tabular}


We now turn to an examination of the results for Female LFPR for Australia. The similar considerations to the case of total LFPR indicate reductions in the values of $d$ under which the null hypothesis are not rejected. The last column of Panel (a) indicates a value of 0.40 for $d$ that is not rejected and Panel (b) leads to values of 0.45 and 0.50 for $d$ that are not rejected. We chose $d=0.45$ as the highest fractional order of integration estimated. These results suggest that the Female LFPR series for Australia is a stationary series with long-memory. Assessment of the results in Table 2 for Male LFPR for Australia indicate that in both Panels (a) and (b) the results are similar to the cases of total and female LFPRs. The last columns of Panels (a) and (b) indicate a value of $d$ equal to 0.15 and 0.25 respectively, which is not rejected. These results suggest that the Male LFPR series for Australia is a stationary series with long-memory.

We next consider the results for total LFPR for Canada in Table 2. As before, the results in Panels (a) and (b) correspond to the white noise and the AR(1) disturbances, respectively. Similar to the case of Australia, we observe reductions in the value of $d$ under the null hypothesis that is not rejected. The last two columns of Panels (a) and (b) indicate a value of $d$ equal to 0.45 and 0.55 respectively, which is not rejected. These results imply that the total LFPR series for Canada is a stationary series with long-memory under the assumption of white noise disturbances while under the assumption of AR(1) disturbances it is non-stationary with infinite variance, but mean reverts in the sense that the impulse response function is decaying. We next consider the results for female LFPR for Canada. Similar considerations apply to this case also. The last two columns of Panel (a) and (b) indicate a value of $d$ equal to 0.40 and 0.50 respectively, which is not rejected. These results imply that the female LFPR series for Canada is a stationary series with longmemory under the assumption of white noise disturbances while under the assumption of $\mathrm{AR}(1)$ disturbances it is non-stationary with infinite variance, but mean reverts in the sense that the impulse response function is decaying. Considering the results for male LFPR for Canada, as before we observe further reductions in the value of $d$ under the null hypothesis that is not rejected. The last two columns of Panel (a) indicates a value of $d$ equal to 0.50 that is not rejected while the last two columns of Panel (b) shows a value of $d$ equal to 0.60 , which is not rejected. These results imply that the male LFPR series for Canada is non-stationary with infinite variance, but mean reverts in the sense that the impulse response function is decaying. The male subcomponent of total LFPR series for Canada 
seems to have an implied $d$ in the nonstationary region, while the aggregate series has a $d$ in the stationary region under the WN assumption and non-stationary under the AR(1) assumption. This may seem contradictory, since if a sub-component of a series is nonstationary than the series should be non-stationary. Indeed, upper limit of $d$ values accepted for the total LFPR series covers the nonstationary region. In a statistical sense, there is chance that the total series is still nonstationary. However, this situation may occur for two reasons. First, the $d$ value implied by the model in equations (1) and (2) depends on the estimates of the deterministic component parameters $\hat{\beta}$. Second, in the case of AR(1) specification, both the $\mathrm{AR}(1)$ parameter and $d$ will compete for capturing memory. The implied $d$ might be smaller, if a larger $\operatorname{AR}(1)$ parameter is estimated. For the white noise specification, repeating the test with a finer grid of $d_{0}$ values, the lower limit for Canadian male LFPR series is obtained as 0.47. In the case of AR(1) specification, the estimate of the AR(1) parameter for Canadian male LFPR series is 0.0508. Since this is smaller than the estimate 0.0782 for the total series, there will be more memory for $d$ to capture in case of the male LFPR series, leading to a larger $d$ accepted under the null.

The estimation results of total, female and male LFPRs for the USA are presented in Table 2. In all three cases, as before in both Panels (a) and (b) successive introductions of a constant, a linear time trend and various combinations of level and trend shift dummies reduce the values of $d$ that are not rejected. For the total LFPR the last columns of Panels (a) and (b) indicate values of 0.50 and 0.55 , respectively, for $d$ under the null hypothesis that is not rejected. These results mean that the total LFPR series for the USA is nonstationary series with infinite variance, but mean reverts in the sense that the impulse response function is decaying under the both assumptions about the disturbances. For the female LFPR the last three columns of Panels (a) and (b) indicate values of 0.55 and 0.60 , respectively, for $d$ under the null hypothesis that is not rejected. These results mean that the female LFPR series for the USA is non-stationary series with infinite variance, but mean reverts in the sense that the impulse response function is decaying under the both assumptions about the disturbances. For the male LFPR the last two columns of Panels (a) and the last column of Panel (b) indicate values of 0.45 and 0.50 , respectively, for $d$ under the null hypothesis that is not rejected. These results mean that the male LFPR series for the USA is stationary under the White Noise disturbances while under the AR(1) disturbances, it is non-stationary series with infinite variance, but mean reverts in the sense 
that the impulse response function is decaying under the both assumptions about the disturbances.

In order to estimate the appropriate order of integration more precisely, we recompute the Robinson (1994) tests using a finer grid for values of $d_{0}=0.20,0.21, \ldots, 1.30$. In this way, we construct an acceptable confidence interval for the null hypothesis of a unit root. Table 3 reports the confidence intervals of those values of $d_{0}$, where $\mathrm{H}_{0}: d=d_{0}$ cannot be rejected at the 5\% significance level for different samples and different types of regressors. We construct these intervals as follows. Starting from the first value of $d$ in the grid, we form the statistic to test the null for this value. This value of $d$ is discarded, if the null is rejected at the $5 \%$ level. Otherwise, the value is retained. We repeat this sequentially for all values of $d$ in the grid and construct an interval between the lowest and highest nonrejection values of $d$. These confidence intervals for all cases of the deterministic regressors are presented in Table 3. The first three cases ignore the structural breaks and allow only a constant and a constant plus a linear trend, respectively. The last three cases include structural break variables in the deterministic component in order to remove the impact of shifts in the mean and the growth rate. The confidence intervals are close and within \pm 0.04 of the non-rejected values of $d$ in Table 2 . The differences between upper and lower limits in Table 2 and 3 are all due to finer grid of $d_{0}$ values used for constructing the confidence intervals. 
Table 3: Confidence Intervals for Order of Fractional Integration for total, female and male LFPR of Australia, Canada and the USA

\begin{tabular}{|c|c|c|c|c|c|c|c|}
\hline & $z_{t}=0$ & $z_{t}=1$ & $z_{t}=(1, t)^{\prime}$ & $z_{t}=z_{1 t}$ & $z_{t}=z_{2 t}$ & $z_{t}=z_{3 t}$ & \\
\hline \multicolumn{8}{|c|}{ Panel (a): Disturbances in equation (2) are assumed to be white noise } \\
\hline \multicolumn{8}{|l|}{ Australia } \\
\hline Total & {$[0.94(0.97) 1.02]$} & {$[0.94(0.96) 1.02]$} & {$[0.94(0.97) 1.01]$} & {$\left[\begin{array}{llll}0.39 & (0.44) & 0.48\end{array}\right]$} & {$\left[\begin{array}{llll}0.34 & (0.41) & 0.49\end{array}\right]$} & {$[0.29(0.38)$} & $0.48]$ \\
\hline Female & {$\left[\begin{array}{lll}0.93 & (0.96) & 1.01\end{array}\right]$} & {$[0.92(0.96) 1.00]$} & {$\left[\begin{array}{lll}0.76 & (0.78) & 0.82\end{array}\right]$} & {$\left[\begin{array}{llll}0.41 & (0.48) & 0.56\end{array}\right]$} & {$\left[\begin{array}{lll}0.40 & (0.47) & 0.53\end{array}\right]$} & {$[0.40(0.45)$} & $0.52]$ \\
\hline Male & {$[0.94(0.98) 1.02]$} & {$[0.94(0.98) 1.02]$} & {$\left[\begin{array}{lll}0.64 & (0.69) & 0.72\end{array}\right]$} & {$\left[\begin{array}{lll}0.30 & (0.37) & 0.44\end{array}\right]$} & {$\left[\begin{array}{lll}0.24 & (0.31) & 0.39\end{array}\right]$} & {$[0.18(0.25)($} & $0.33])$ \\
\hline \multicolumn{8}{|l|}{ Canada } \\
\hline Total & {$\left[\begin{array}{lll}0.95 & (0.98) & 1.01\end{array}\right]$} & {$\left[\begin{array}{llll}0.96 & (0.98) & 1.00\end{array}\right]$} & {$\left[\begin{array}{lll}0.96 & (0.99) & 1.03\end{array}\right]$} & {$\left[\begin{array}{llll}0.56 & (0.61) & 0.67\end{array}\right]$} & {$\left[\begin{array}{llll}0.47 & (0.55) & 0.63\end{array}\right]$} & {$[0.48(0.54)$} & $0.64]$ \\
\hline Female & {$\left[\begin{array}{llll}0.94 & (0.98) & 1.02\end{array}\right]$} & {$\left[\begin{array}{llll}0.95 & (0.97) & 1.00\end{array}\right]$} & {$\left[\begin{array}{llll}0.95 & (0.98) & 1.01\end{array}\right]$} & {$\left[\begin{array}{llll}0.54 & (0.60) & 0.64\end{array}\right]$} & {$\left[\begin{array}{llll}0.44 & (0.54) & 0.62\end{array}\right]$} & {$[0.44(0.53)$} & $0.57]$ \\
\hline Male & {$\left[\begin{array}{lll}0.94 & (0.97) & 1.02\end{array}\right]$} & {$\left[\begin{array}{llll}0.88 & (0.91) & 0.94\end{array}\right]$} & {$\left[\begin{array}{lll}0.89 & (0.92) & 0.94\end{array}\right]$} & {$\left[\begin{array}{llll}0.58 & (0.62) & 0.68\end{array}\right]$} & {$\left[\begin{array}{lll}0.46 & (0.55) & 0.63\end{array}\right]$} & {$[0.48(0.55)$} & $0.64]$ \\
\hline \multicolumn{8}{|l|}{ USA } \\
\hline Total & {$\left[\begin{array}{lll}0.96 & (0.99) & 1.03\end{array}\right]$} & {$\left[\begin{array}{llll}0.85 & (0.87) & 0.89\end{array}\right]$} & {$\left[\begin{array}{llll}0.76 & (0.78) & 0.81\end{array}\right]$} & {$\left[\begin{array}{llll}0.55 & (0.60) & 0.66\end{array}\right]$} & {$\left[\begin{array}{lll}0.54 & (0.57) & 0.62\end{array}\right]$} & {$[0.50(0.53)$} & $0.59]$ \\
\hline Female & {$\left[\begin{array}{lll}0.97 & (0.99) & 1.01\end{array}\right]$} & {$\left[\begin{array}{llll}0.92 & (0.96) & 1.00\end{array}\right]$} & {$\left[\begin{array}{lll}0.76 & (0.78) & 0.80\end{array}\right]$} & {$\left[\begin{array}{lll}0.54 & (0.61) & 0.66\end{array}\right]$} & {$\left[\begin{array}{lll}0.54 & (0.58) & 0.63\end{array}\right]$} & {$[0.48(0.55)$} & $0.58]$ \\
\hline Male & {$\left[\begin{array}{lll}0.96 & (0.98) & 1.00\end{array}\right]$} & {$\left[\begin{array}{llll}0.93 & (0.96) & 1.01\end{array}\right]$} & {$\left[\begin{array}{lll}0.73 & (0.75) & 0.79\end{array}\right]$} & {$\left[\begin{array}{llll}0.54 & (0.59) & 0.64\end{array}\right]$} & {$\left[\begin{array}{lll}0.48 & (0.51) & 0.57\end{array}\right]$} & {$[0.47(0.50)$} & $0.56]$ \\
\hline \multicolumn{8}{|c|}{ Panel (b): Disturbances in equation (2) are assumed to be an AR(1) process } \\
\hline \multicolumn{8}{|l|}{ Australia } \\
\hline Total & {$\left[\begin{array}{lll}1.03 & (1.09) & 1.18\end{array}\right]$} & {$\left[\begin{array}{lll}0.77 & (0.81) & 0.84\end{array}\right]$} & {$\left[\begin{array}{lll}0.72 & (0.70) & 0.74\end{array}\right]$} & {$\left[\begin{array}{llll}0.38 & (0.41) & 0.47\end{array}\right]$} & {$[0.34(0.38) 0.41]$} & {$[0.35(0.39)$} & $0.43]$ \\
\hline Female & {$[1.04(1.11) 1.18]$} & {$\left[\begin{array}{lll}0.88 & (0.93) & 0.96\end{array}\right]$} & {$\left[\begin{array}{lll}0.71 & (0.75) & 0.79\end{array}\right]$} & {$\left[\begin{array}{lll}0.42 & (0.48) & 0.53\end{array}\right]$} & {$\left[\begin{array}{lll}0.47 & (0.50) & 0.52\end{array}\right]$} & {$[0.37(0.42)$} & $0.46]$ \\
\hline Male & {$\left[\begin{array}{lll}1.02 & (1.09) & 1.16\end{array}\right]$} & {$[0.78(0.80) 0.82]$} & {$\left[\begin{array}{lll}0.61 & (0.64) & 0.68\end{array}\right]$} & {$\left[\begin{array}{lll}0.27 & (0.33) & 0.38\end{array}\right]$} & {$\left[\begin{array}{lll}0.27 & (0.31) & 0.33\end{array}\right]$} & {$[0.26(0.28)$} & $0.31]$ \\
\hline \multicolumn{8}{|l|}{ Canada } \\
\hline Total & {$\left[\begin{array}{lll}1.05 & (1.11) & 1.21]\end{array}\right.$} & {$\left[\begin{array}{llll}0.97 & (1.02) & 1.09\end{array}\right]$} & {$\left[\begin{array}{lll}0.91 & (0.95) & 0.98\end{array}\right]$} & {$\left[\begin{array}{llll}0.58 & (0.60) & 0.63\end{array}\right]$} & {$\left[\begin{array}{llll}0.54 & (0.58) & 0.62\end{array}\right]$} & {$[0.49(0.54)$} & $0.59]$ \\
\hline Female & {$\left[\begin{array}{lll}1.05 & (1.11) & 1.21\end{array}\right]$} & {$\left[\begin{array}{llll}0.96 & (1.03) & 1.09\end{array}\right]$} & {$\left[\begin{array}{llll}0.99 & (1.02) & 1.04\end{array}\right]$} & {$\left[\begin{array}{llll}0.51 & (0.54) & 0.58\end{array}\right]$} & {$\left[\begin{array}{lll}0.48 & (0.53) & 0.58\end{array}\right]$} & {$[0.47(0.52)$} & $0.57]$ \\
\hline Male & {$\left[\begin{array}{lll}1.02 & (1.12) & 1.17\end{array}\right]$} & {$\left[\begin{array}{llll}0.80 & (0.87) & 0.92\end{array}\right]$} & {$\left[\begin{array}{lll}0.80 & (0.88) & 0.95\end{array}\right]$} & {$\left[\begin{array}{llll}0.57 & (0.61) & 0.64\end{array}\right]$} & {$\left[\begin{array}{lll}0.57 & (0.62) & 0.66\end{array}\right]$} & {$[0.56(0.59)$} & $0.64]$ \\
\hline \multicolumn{8}{|l|}{ USA } \\
\hline Total & {$\left[\begin{array}{lll}1.02 & (1.09) & 1.13\end{array}\right]$} & {$\left[\begin{array}{llll}0.83 & (0.85) & 0.89\end{array}\right]$} & {$\left[\begin{array}{llll}0.99 & (1.04) & 1.10\end{array}\right]$} & {$\left[\begin{array}{llll}0.57 & (0.62) & 0.64\end{array}\right]$} & {$\left[\begin{array}{llll}0.58 & (0.60) & 0.62\end{array}\right]$} & {$[0.53(0.56)$} & $0.60]$ \\
\hline Female & {$\left[\begin{array}{lll}1.02 & (1.07) & 1.10\end{array}\right]$} & {$\left[\begin{array}{llll}0.96 & (1.01) & 1.08\end{array}\right]$} & {$\left[\begin{array}{lll}0.97 & (1.02) & 1.11\end{array}\right]$} & {$\left[\begin{array}{llll}0.56 & (0.60) & 0.66\end{array}\right]$} & {$\left[\begin{array}{lll}0.37 & (0.60) & 0.63\end{array}\right]$} & {$[0.53(0.57)$} & $0.62]$ \\
\hline Male & {$\left[\begin{array}{lll}1.04 & (1.08) & 1.13\end{array}\right]$} & {$\left[\begin{array}{lll}0.92 & (0.95) & 0.99\end{array}\right]$} & {$\left[\begin{array}{lll}0.97 & (1.04) & 1.10\end{array}\right]$} & {$\left[\begin{array}{llll}0.51 & (0.54) & 0.59\end{array}\right]$} & {$\left[\begin{array}{lll}0.51 & (0.55) & 0.58\end{array}\right]$} & {$\left[\begin{array}{ll}0.51 & (0.54)\end{array}\right.$} & $0.59]$ \\
\hline
\end{tabular}


We also evaluate the estimates of impulse-response coefficients of the ARFIMA models and the fraction of the time needed for dissipation of the effects of a shock in the total, female and male LFPR series of Australia, Canada and the USA with white noise and AR(1) disturbances. The estimates of impulse responses may be biased particularly in small samples in long-memory models. The biases and the dependence of the impulse responses on the initial conditions can be controlled by calculating the generalized impulse responses $\left(c_{k}=\partial y_{t+k} / \partial \varepsilon_{t}\right)$ of Pesaran and Shin (1998) and the measure of persistence $\tau_{\alpha}$ using bootstrap method. Standard errors of the impulse response functions are also obtained by means of bootstrap. The 95 percent confidence intervals are obtained via a parametric bootstrap with 5000 replications. Inferences on persistence are based on these results.

In the evolution of the impulse response function we use the highest $d$ values that are not rejected at 5 percent significance level and the first order correlation coefficient values computed from the $\mathrm{AR}(1)$ residuals. These values are given in Table 4. $d$-WN and $d$-AR(1) are the values that we select using the results in Table 2. We note two points here: one is that the range of values of non-rejection for $d$ are narrower under the assumption of AR(1) disturbances than under the assumption of WN disturbances. Second, the first order correlation coefficient estimates are rather very small. Using the parameter estimates given in Table 4, the generalised impulse responses and their 95 percent bootstrap confidence intervals for LFPR series are given in Figure 4. Confidence intervals bracket zero for all series when impulse responses are evaluated at less than or equal to $k=1200$ (100 years) under the WN assumptions. These results imply the effects of the shocks are temporary and the series are mean-reverting. Under the WN disturbance assumption the confidence intervals are tighter than under the $\mathrm{AR}(1)$ assumption. Under the assumption of $\mathrm{AR}(1)$ process the effect of the shocks take longer time to disappear implying that the series are mean-reverting, but with longer memory or stronger persistence than under the assumption of WN disturbances. 
Table 4: Parameter Estimates Used for Bootstrap Impulse Responses

\begin{tabular}{lccc}
\hline & $d$-WN & $d$-AR(1) & AR(1) \\
\hline Australia & & & 0.0368 \\
\hline Total & 0.35 & 0.35 & 0.0657 \\
Female & 0.40 & 0.45 & 0.0291 \\
Male & 0.15 & 0.25 & \\
\hline Canada & & & 0.0782 \\
\hline Total & 0.45 & 0.55 & 0.0857 \\
Female & 0.40 & 0.50 & 0.0508 \\
Male & 0.50 & 0.60 & 0.0291 \\
\hline USA & & & -0.0188 \\
\hline Total & 0.50 & 0.55 & 0.0598 \\
Female & 0.55 & 0.60 & \\
Male & 0.45 & 0.50 &
\end{tabular}

Figure 4: Generalised Impulse-response analysis for Australia Panel (A): Total LFPR
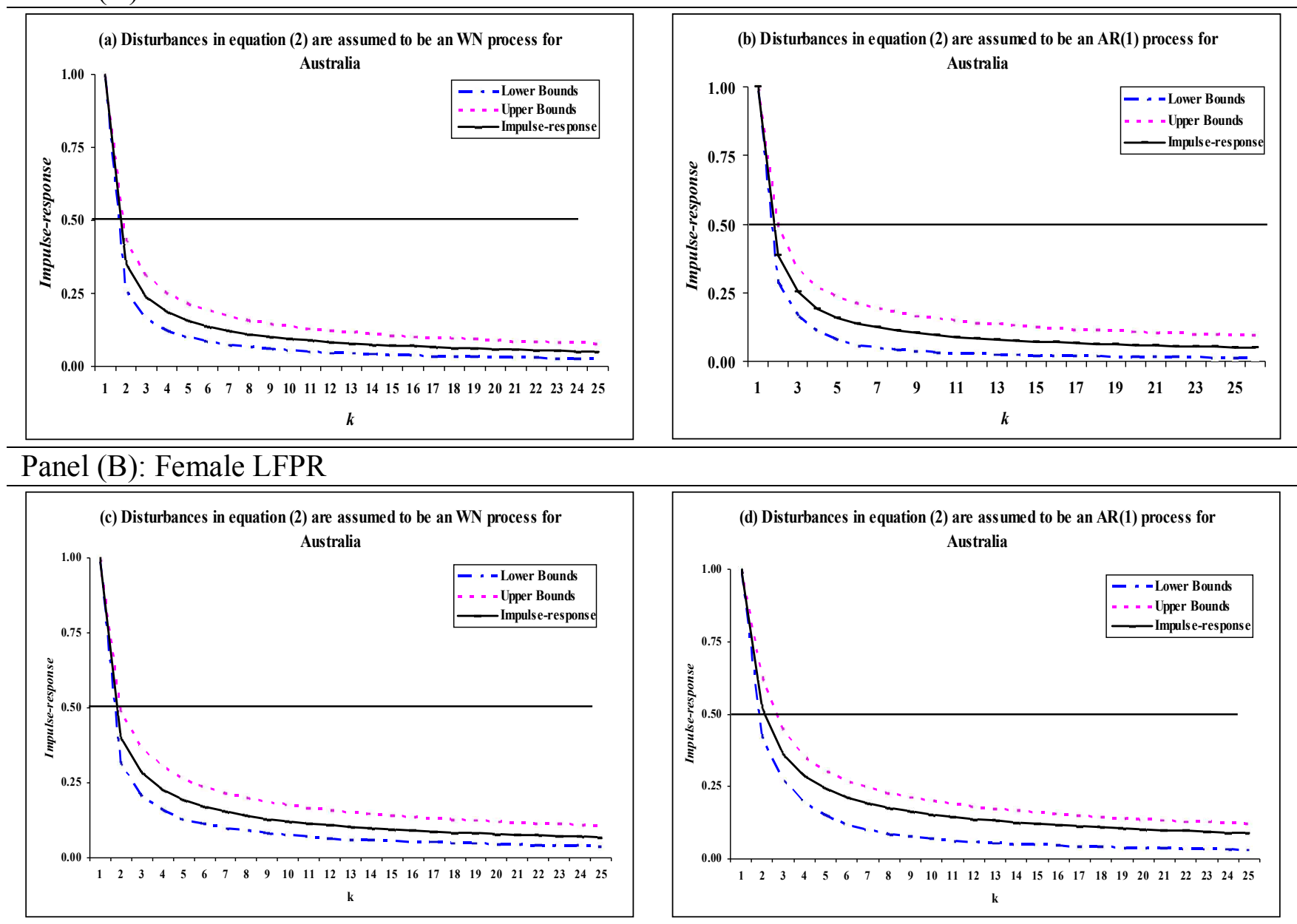

Panel (C): Male LFPR 


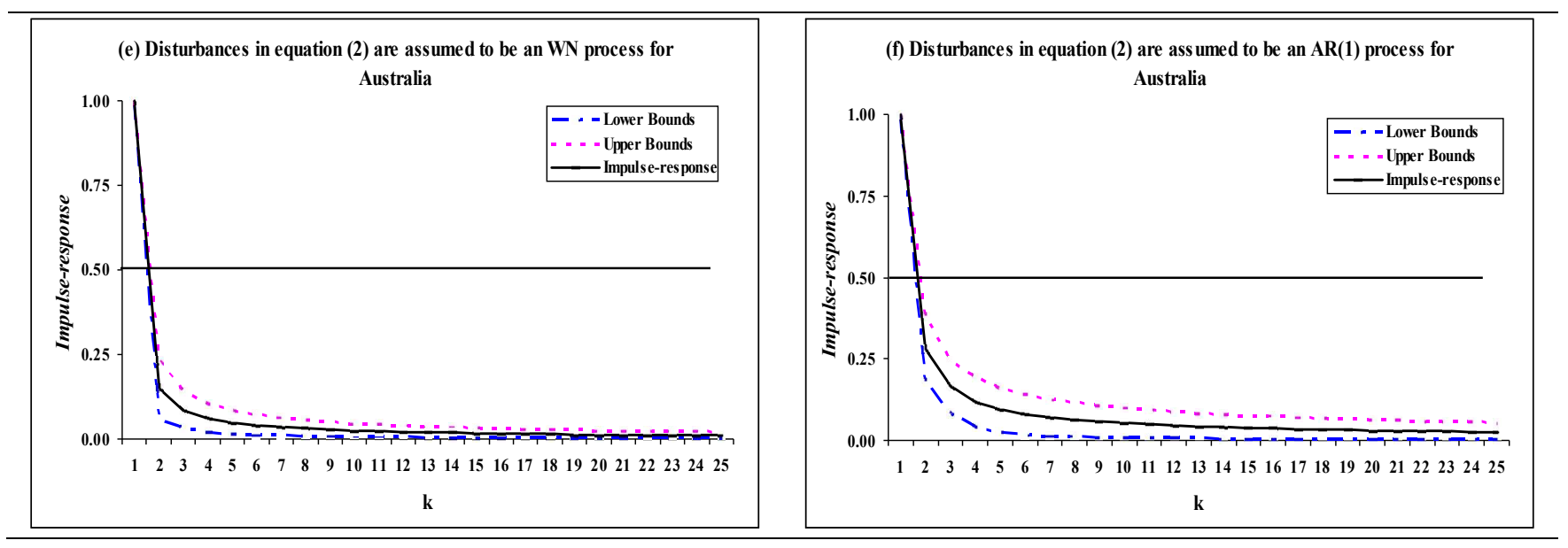

Figure 5: Generalised Impulse-response analysis for Canada
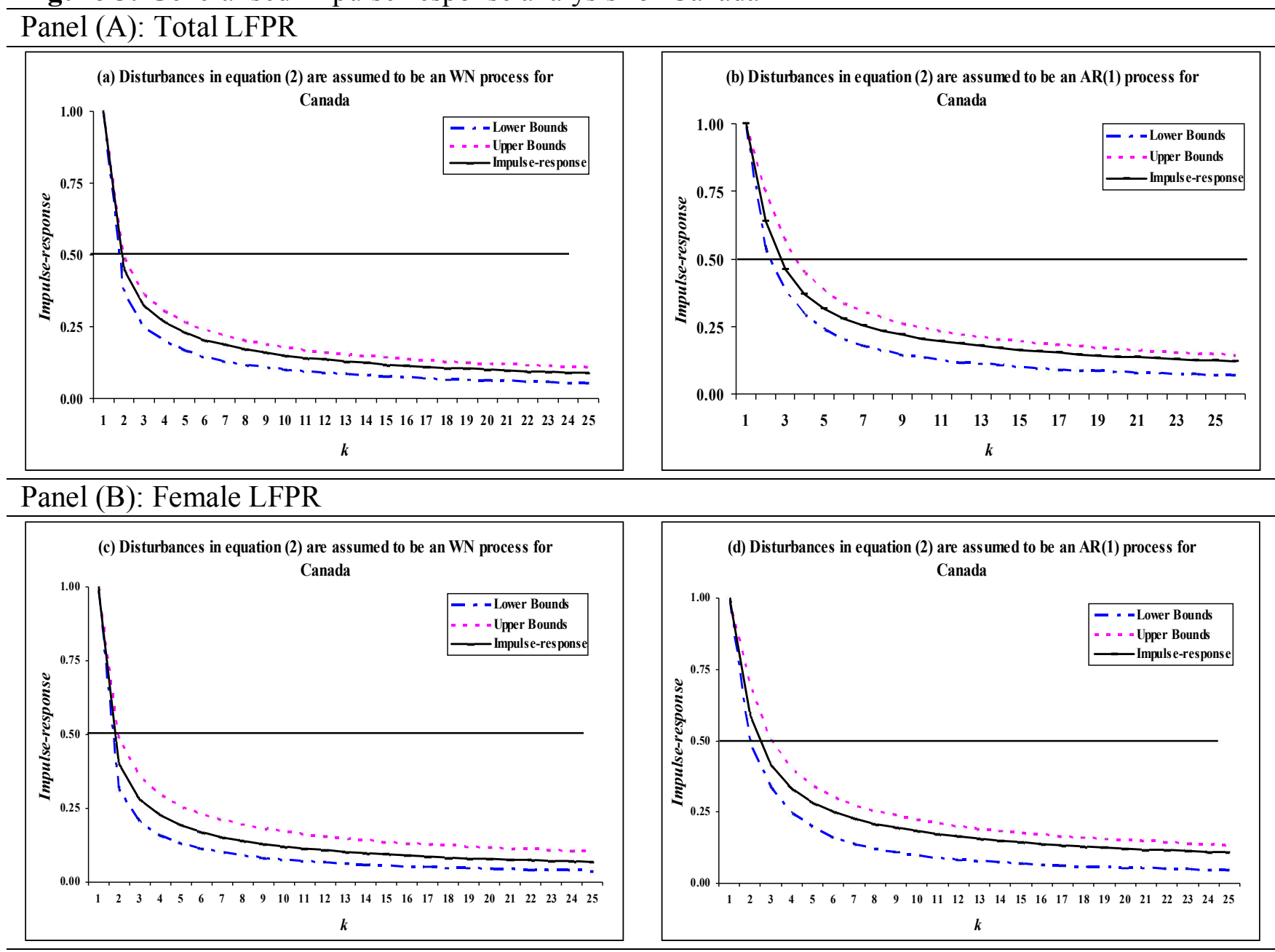

Panel (C): Male LFPR 


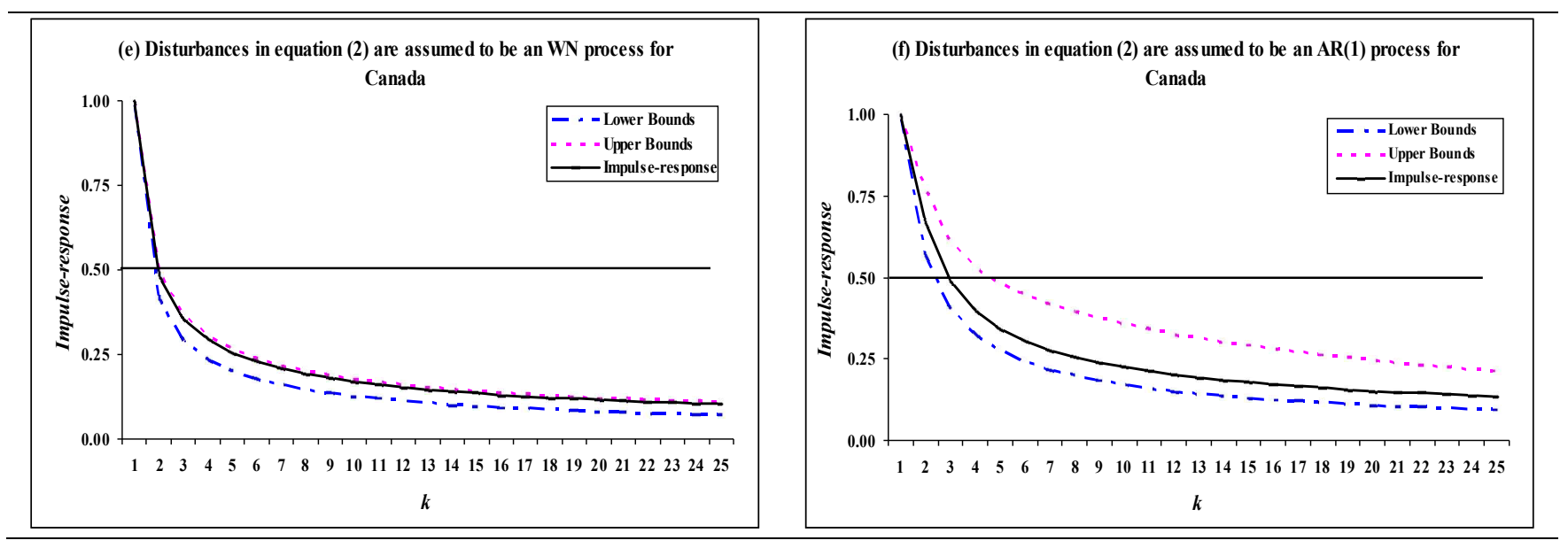

Figure 6: Generalised Impulse-response analysis for USA

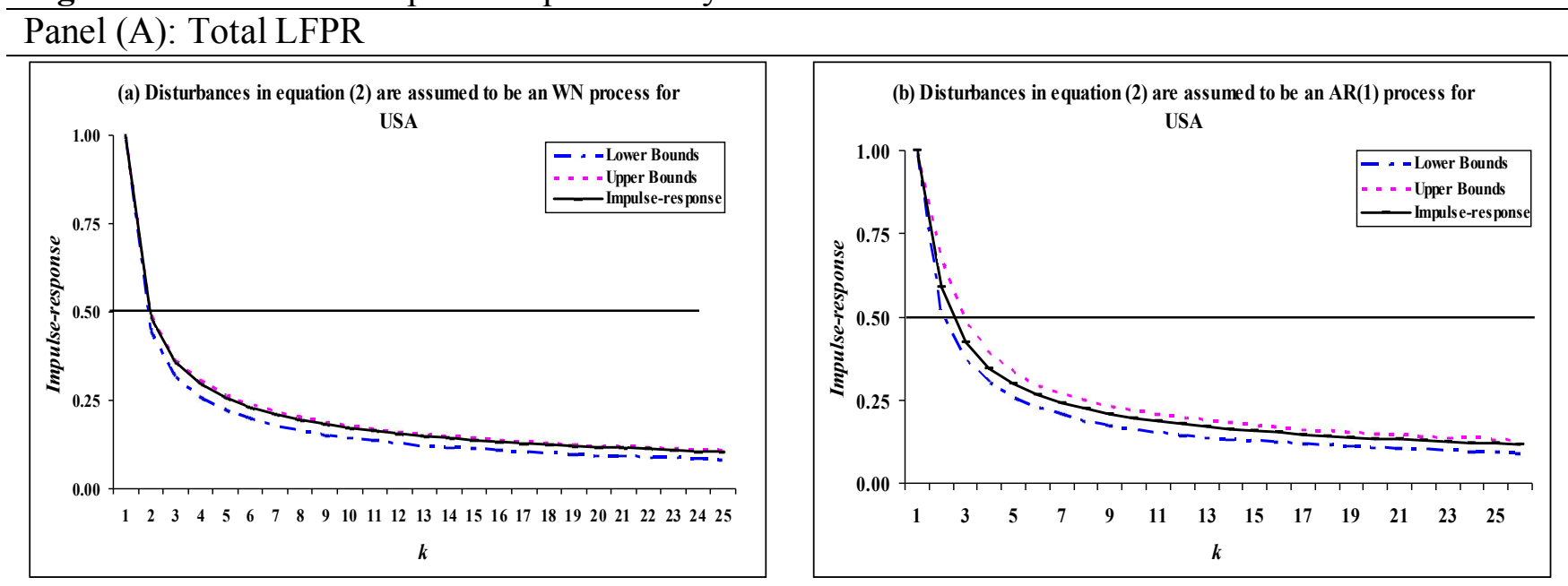

\section{Panel (B): Female LFPR}

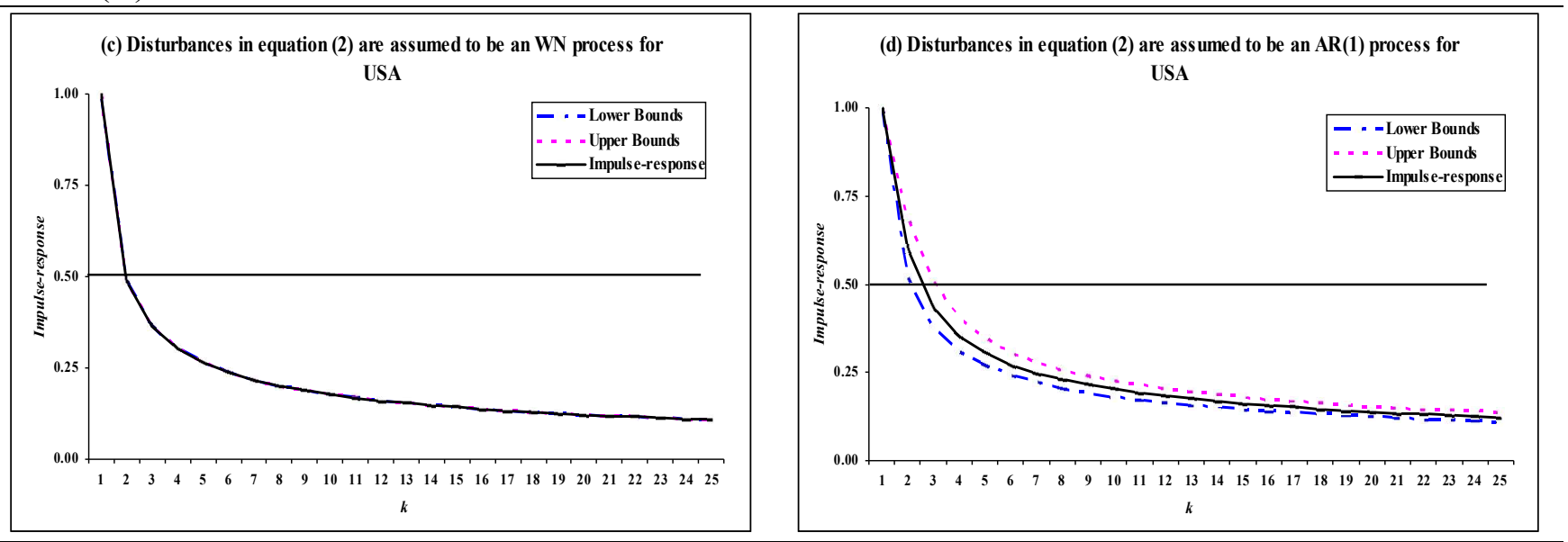

Panel (C): Male LFPR 


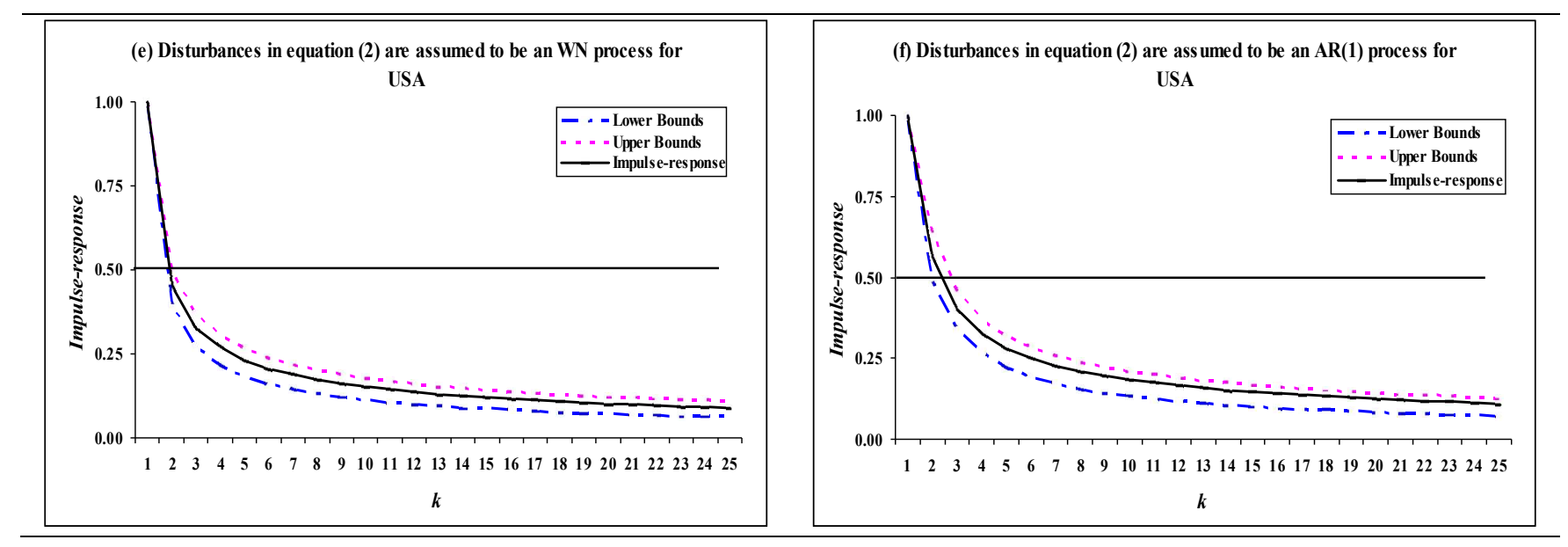

Table 5 presents the estimates of $\tau_{\alpha}$ for the total, female and male LFPR series. Estimates for $\tau_{\alpha}$ show that a period of maximum two months is required for 30 percent of the effects of shocks to disappear for the total, female and male series for all countries under the WN and AR(1) disturbances assumption. For 50 percent of the effects of shocks to disappear a period of two months is required for the total, female and male for Australia, two months for total and female and three months for male for Canada and three months for total and female and two months for male under the WN disturbances. While under the AR(1) disturbances two months (three months for female) required for Australia, three months is required in Canada (four months for male) and the USA. About two years in total, three and a half years in female and five months in male LFPR in Australia, about five and a half, three and a half years for female, 10 years for total, female and male LFPR respectively, in Canada and about 10, 22.5 and 5.5 years for total, female and male LFPR respectively, for the USA are required for 95 percent of the effects of shocks to disappear under the WN disturbances assumption. However, under the AR(1) assumption the number of months required for the effect of shocks to disappear are substantially longer than under the WN assumption. For example, it takes about 2.25, 6 and 1 years, respectively for the total, female and male LFPR in Australia and about 27, 13 and 63 years, respectively for the total, female and male LFPR in Canada and about 24, 58 and 12 years, respectively for the total, female and male in the USA are required for 95 percent of the effects of shocks to disappear under the $\mathrm{AR}(1)$ disturbances assumption. These results imply that all of the total, female and male LFPR series of these countries are mean-reverting with longmemory. 
Table 5: Time required for $\alpha$ percent of the full effect of a unit shock to LFPR disappear $\left(\tau_{\alpha}\right)$

\begin{tabular}{|c|c|c|c|c|c|}
\hline Countries & $\alpha=0.30$ & $\alpha=0.50$ & $\alpha=0.80$ & $\alpha=0.90$ & $\alpha=0.95$ \\
\hline \multicolumn{6}{|c|}{ (a) Estimates for disturbances in equation (10) are assumed to be white noise } \\
\hline \multicolumn{6}{|l|}{ Australia } \\
\hline Total & 2 & 2 & 4 & 10 & 25 \\
\hline Female & 2 & 2 & 5 & 14 & 40 \\
\hline Male & 2 & 2 & 2 & 3 & 5 \\
\hline \multicolumn{6}{|l|}{ Canada } \\
\hline Total & 2 & 2 & 7 & 20 & 69 \\
\hline Female & 2 & 2 & 5 & 14 & 40 \\
\hline Male & 2 & 3 & 9 & 33 & 129 \\
\hline \multicolumn{6}{|l|}{$U S A$} \\
\hline Total & 2 & 3 & 9 & 33 & 129 \\
\hline Female & 2 & 3 & 14 & 59 & 269 \\
\hline Male & 2 & 2 & 7 & 20 & 69 \\
\hline \multicolumn{6}{|c|}{ (b) Estimates for disturbances in equation (10) are assumed to be an AR(1) process } \\
\hline \multicolumn{6}{|l|}{ Australia } \\
\hline Total & 2 & 2 & 4 & 10 & 27 \\
\hline Female & 2 & 3 & 8 & 23 & 78 \\
\hline Male & 2 & 2 & 3 & 5 & 12 \\
\hline \multicolumn{6}{|l|}{ Canada } \\
\hline Total & 2 & 3 & 16 & 70 & 322 \\
\hline Female & 2 & 3 & 11 & 39 & 154 \\
\hline Male & 2 & 4 & 25 & 134 & 754 \\
\hline \multicolumn{6}{|l|}{$U S A$} \\
\hline Total & 2 & 3 & 14 & 63 & 288 \\
\hline Female & 2 & 3 & 21 & 113 & 632 \\
\hline Male & 2 & 3 & 10 & 37 & 145 \\
\hline
\end{tabular}

Notes: Time required is measured in the frequency of the corresponding series, i.e., months.

\section{Conclusion}

This paper extends the previous research by considering the labour force participation rate (LFPR) series for Australia, Canada and the USA by gender using fractionally integrated models with endogenously determined multiple structural breaks. Gustavsson and Österholm (2006) are the first researchers to point out that if LFPR series are nonstationary, then unemployment rates are "uninformative". They investigate whether or not LFPR series for Australia, Canada and the USA are non-stationary. Their finding of nonstationarity which implies that the informational value of unemployment may be doubtful 
is also partially supported by Madsen et al. (2008) who reported that the evidence is at best mixed about the informational value of unemployment rates. Gustavsson and Österholm (2010) maintain their conclusion for the LFPR series disaggregated by gender, race and age for the USA. In this paper, we show that the apparent non-stationarity in the LFPR series found by previous researchers disappears when the fractionally integrated processes with endogenously determined multiple structural breaks are considered. We investigate the time series properties of the total, female and male LFPR series for Australia, Canada and the USA using the score test by Robinson (1994) for fractional integration under endogenously determined multiple structural breaks in the series. Our findings indicate that under the assumption of white noise disturbances the total, female and male participation rates in Australia and the total and female participation rates in Canada and the male participation rate for the USA are stationary while the male participation rate for Canada and the total and female participation rates for the USA are non-stationary but meanreverting. Under the assumption of $\mathrm{AR}(1)$ process the total, female and male participation rate series of Australia are still all stationary while the total, female and male participation rate series for Canada and the USA are all non-stationary but mean-reverting. Our conclusions are supported by the generalized impulse responses due to Pesaran and Shin (1998). These findings contradict the results of Gustavsson and Österholm who find that total participation rate series are non-stationary and Madsen et al. who find at best mixed evidence on the time series properties of the total participation rate series except that for the USA which they find is mean-reverting as we do in this paper. We find that endogenously determined multiple structural breaks affect the degree of integration of the LFPR series rendering them stationary or at best mean-reverting. Our results imply that unemployment rates are informative about joblessness and that long-term changes in unemployment rates explain long-term changes in employment rates implying one-to-one correspondence between them. 


\section{REFERENCES}

Anderson P.,Gustman, A.and Steinmeier, T. 1997. Trends in male labour force participation and retirement: some evidence on the role of pensions and social security in the 1970s and 1980s. NBER Working paper 6208, October.

Bai, J. and J. Perron, 1998. Estimating and testing linear models with multiple structural changes. Econometrica, 66, 47-78.

Balcilar, M. 1996. Efficient and Near Efficient Unit Root Tests in Models with Structural Change. Ph.D. Dissertation, Wayne State University.

Banerjee, A., Lumsdaine, R.L. and Stock, J.H. 1992. Recursive and sequential tests of the unit-root and trend-break hypotheses: theory and international evidence. Journal of Business and Economic Statistics, 10, 271-287.

Baum, C.F.; J.T. Barkoulas; and M. Caglayan. 1999. Persistence in International Inflation Rates. Southern Economic Journal 65, 900-913.

Bos, C.; P.H. Franses; and M. Ooms. 1999. Long Memory and Level Shifts: Reanalyzing Inflation Rates. Empirical Economics 24, 427-449.

Bhattacharya, R.N. and V.K. Gupta and Waymire, E., 1983. The Hurst effect under trends. Journal of Applied Probability, 20, 649-662.

Caner, M. and Hansen, B.E. 2001. Threshold Autoregression with a Unit Root. Econometrica, vol. 69,

no. 6 , pp. $1555-1596$.

Christiano, L. J. 1992. Searching for a Break in GNP. Journal of Business and Economic Statistics. 10:3, pp. 237-50.

Clemente, J., Montanes, A. and Reyes, M. 1998. Testing for a unit root in variables with a double change in the mean. Economics Letters, 59, 175-182.

Dickey, D., and W.A. Fuller. 1979. Distributions of the Estimators for Autoregressive Time Series with a Unit Root. Journal of the American Statistical Association 74, 427-431.

Diebold, F.X., and A. Inoue. 2001. Long Memory and Regime Switching. Journal of Econometrics 105, 131159.

Elliott, G., Rothenberg, T.J., Stock, J.H., 1996. Efficient tests for an autoregressive unit root. Econometrica 64, 813-836.

Engle, R.F., and A.D. Smith. 1999. Stochastic Permanent Breaks. Review of Economics and Statistics 81, 553-574.

Gil-Alana, L.A. 1999. Testing of Fractional Integration with Monthly Data. Economic Modelling 16, 613-629.

Gil-Alana, L.A. 2001a. A Fractionally Integrated Model with a Mean Shift for the US and the UK Real Oil Prices. Economic Modelling 18, 643-658.

Gil-Alana, L.A. 2001b. Testing of Stochastic Cycles in Macroeconomic Time Series. Journal of Time Series Analysis 22, 411-430.

Gil-Alana, L.A. 2002. Structural Breaks and Fractional Integration in the US Output and Unemployment Rate. Economics Letters 77, 79-84.

Gil-Alana, L.A. 2003. Testing of unit roots and other fractionally integrated hypothesis in the presence of structural breaks. Empirical Economics, 28, 101-13.

Gil-Alana, L.A. 2008. Fractional Integration and Structural Breaks at Unknown Periods of Time. Journal of Time Series Analysis, 29, 163-185.

Gil-Alana, L.A., and Robinson, P.M. 1997. Testing of Unit Roots and Other Nonstationary Hypotheses in Macroeconomic Time Series. Journal of Econometrics 80, 241-268.

Gil-Alana, L.A. and Robinson, P.M., 2001. Testing seasonal fractional integration in the UK and Japanese consumption and income. Journal of Applied Econometrics, 16, 95-114.

Gustavsson, M. and Österholm, P. 2006. The Informational Value of Unemployment Statistics: A Note on the Time Series Properties of Participation Rates. Economics Letters, 92, 428-433.

Gustavsson, M. and Österholm, P., 2007. Does Unemployment Hysteresis Equal Employment Hysteresis?. Economic Record, 83, 159-173.

Gustavsson, M. and Österholm, P., 2010. Labor-Force Participation Rates and the Informational Value of Unemployment Rates: Evidence from Disaggregated US Data. Stockholm: The National Institute of Economics Research (NIER), Working Paper No. 120, 1-18.

Granger, C.W.J., 1980. Long memory relationships and the aggregation of dynamic models. Journal of Econometrics, 14, 227-238.

Granger, C.W.J., and Joyeux, R. 1980. An Introduction to Long-Memory Time Series Models and Fractional Differencing. Journal of Time Series Analysis 1, 15-29.

Granger, C.W.J. and Hyung, H., 2004. Occasional structural breaks and long memory with an application to the S\&P 500 absolute stock returns. Journal of Empirical Finance, 11, 399-421. 
Hidalgo, J., and Robinson, P.M. 1996. Testing for Structural Change in Long Memory Environment. Journal of Econometrics 70, 159-174.

Hosking, J. 1981. Fractional Differencing. Biometrika 68, 165-176.

Im, K.S., Pesaran, M.H., Shin, Y., 2003. Testing for unit roots in heterogeneous panels. Journal of Econometrics 115, 53-74.

Johansen, S., 1988. Statistical analysis of cointegration vectors. Journal of Economic Dynamics and Control 12, 231-254.

Kapetanios, G., Shin, Y., Snell, A., 2003. Testing for a unit root in the nonlinear STAR framework. Journal of Econometrics 112, 359-379.

Kapetanois, G. 2005. Unit root testing against the alternative hypothesis of up to $m$ structural breaks. Journal of Time Series Analysis, 26, 123-133.

Klemes, V. 1974. The Hurst Phenomenon. A Puzzle?. Water Resources Research 10, 675-688.

Krämer, W. and Sibbertsen, P., 2002. Testing for structural changes in the presence of long memory. International Journal of Business and Economics, 1, 235-242.

Kuan, C.M. and Hsu, C.C., 1998. Change point estimation of fractionally integrated processes. Journal of Time Series Analysis, 19, 693-708.

Künsch, H. 1986. Discrimination between Monotonic Trends and Long-Range Dependence. Journal of Applied Probability 23, 1025-1030.

Kwiatkowski, D., Phillips, P.C.B., Schmidt, P., Shin, Y., 1992. Testing the null hypothesis of stationarity against the alternative of a unit root: how sure are we that economic time series have a unit root?Q Journal of Econometrics 54, 159-178.

Lee, J. and Strazicich, M.C. 2003, 'Minimum Lagrange Multiplier Unit Root Test with Two Structural Breaks', Review of Economics and Statistics, vol. 85, no. 4, pp. 1082-1089.

Lee, J. and Strazicich, M.C. 2004, 'Minimum LM Unit Root Test with One Structural Break', manuscript, Department of Economics Working Paper No: 04-17, Appalachian State University.

Lobato, I.N., and Savin, N.E. 1998. Real and Spurious Long Memory Properties of Stock Market Data. Journal of Business and Economic Statistics 16, 261-268.

Lumsdaine, R.L. and Papell, D.H. 1997. Multiple trend breaks and the unit-root hypothesis. Review of Economics and Statistics, 79, 212-218.

Madsen, J., Mishra, V., and Smyth, R. 2008. Are Labour Force Participation Rates Non-Stationary? Evidence from 130 Years for G7 Countries. Australian Economic Papers, 17, 166-189.

Ohanissian, A., Russell, J.R. and Tsay, R.S., 2008. True or spurious long memory? A new test. Journal of Business and Economics Statistics, 26, 161-175.

Ohara, H.I. 1999. A unit root test with multiple trend breaks: a theory with an application to US and Japanese macroeconomic time series. Japanese Economic Review, 50, 266-290.

Ozdemir, Z.A., Balcilar, M., and Tansel, A. 2010. Are Labor Force Participation Rates Stationarity? Evidence from Australia, Canada and the USA. mimeo. Department of Economics, Middle East Technical University, Ankara.

Parke, W.R. 1999. What is fractional integration?, The Review of Economics and Statistics 81, 632-638.

Pesaran, H.H. and Shin, Y. 1998. Generalized impulse response analysis in linear multivariate models. Economics Letters, 58, 17-29.

Perron, P. 1989. The Great Crash, the Oil-Price Shock, and the Unit Root Hypothesis. Econometrica 57, 1361-1401.

Perron, P., 1997. Further Evidence on Breaking Trend Functions in Macroeconomic Variables. Journal of Econometrics, 80, 355-386.

Perron, P. and Vogelsang, T.J. 1992. Nonstationarity and level shifts with an application to purchasing power parity. Journal of Business and Economic Statistics, 10, 301-320.

Phillips, P.C.B., and P. Perron. 1988. Testing for a Unit Root in a Time Series Regression. Biometrika 75, 335-346.

Robinson, P.M., 1978. Statistical inference for a random coefficient autoregressive model. Scandinavian Journal of Statistics, 5, 163-168.

Robinson, P.M. 1994. Efficient Tests of Nonstationary Hypotheses. Journal of the American Statistical Association 89, 1420-1437.

Said, S.E., Dickey, D.A., 1984. Testing for unit roots in autoregressive moving average models of unknown order. Biometrika 71, 599-607.

Schwarz, G., 1978. Estimating the dimension of a model. Annals of Statistics, 6, 461-4.

Teverovsky, V., and M.S. Taqqu. 1997. "Testing for Long Range Dependence in the Presence of Shifting Means or a Slowly Declining Trend, Using a Variance-Type Estimator.” Journal of Time Series Analysis 18, 279-304. 
Toossi, M. 2002. "A century of change: the U.S. labor force, 1950-2050”, Monthly Labor Review, Vol.125, No:5, 15-28.

Whittle, P. 1951. Hypothesis Testing in Time Series Analysis. Uppsala: Almqvist and Wiksells.

Wright, J.H., 1998. Testing for a structural break at unknown date with long memory disturbances. Journal of Time Series Analysis, 19, 369-376.

Zivot, E. and Andrews, D.W.K. 1992. Further evidence on the great crash, the oil price shock, and the unit root hypothesis. Journal of Business and Economic Statistics, 10, 251-270. 